\title{
Subseasonal variability of low cloud radiative properties over the southeast Pacific Ocean
}

\author{
R. C. George and R. Wood \\ University of Washington, Seattle, Washington, USA \\ Received: 1 October 2009 - Published in Atmos. Chem. Phys. Discuss.: 25 November 2009 \\ Revised: 29 March 2010 - Accepted: 20 April 2010 - Published: 29 April 2010
}

\begin{abstract}
Subseasonal variability of cloud radiative properties in the persistent southeast Pacific stratocumulus deck is investigated using MODIS satellite observations and NCEP reanalysis data. A once-daily albedo proxy is derived based on the fractional coverage of low cloud (a macrophysical field) and the cloud albedo, with the latter broken down into contributions from microphysics (cloud droplet concentration) and macrophysics (liquid water path). Subseasonal albedo variability is dominated by the contribution of low cloud fraction variability, except within $10-15^{\circ}$ of the South American coast, where cloud albedo variability contributes significantly. Covariance between cloud fraction and cloud albedo also contributes significantly and positively to the variance in albedo, which highlights how complex and inseparable the factors controlling albedo are. Droplet concentration variability contributes only weakly to the subseasonal variability of albedo, which emphasizes that attributing albedo variability to the indirect effects of aerosols against the backdrop of natural meteorological variability is extremely challenging.

The dominant large scale meteorological variability is associated with the subtropical high pressure system. Two indices representing changes in the subtropical high strength and extent explain $80-90 \%$ of this variability, and significantly modulate the cloud microphysical, macrophysical, and radiative cloud properties. Variations in droplet concentration of up to $50 \%$ of the mean are associated with the meteorological driving. We hypothesize that these fluctuations in droplet concentration are a result of the large scale meteorology and their correlation with cloud macrophysical properties should not be used as evidence of aerosol effects. Mech-
\end{abstract}

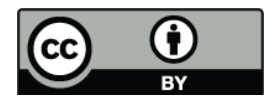

Correspondence to: R. C. George (rheag@atmos.washington.edu) anisms by which large scale meteorology affects cloud properties are explored. Our results support existing hypotheses linking cloud cover variability to changes in cold advection, subsidence, and lower tropospheric stability. Within $10^{\circ}$ of the coast interactions between variability in the surface high pressure system and the orography appear to modulate both cloud macrophysical properties and aerosol transport through suppression of the marine boundary layer depth near the coast. This suggests one possible way in which cloud macrophysical properties and droplet concentration may be correlated independently of the second aerosol indirect effect. The results provide variability constraints for models that strive to represent both meteorological and aerosol impacts on stratocumulus clouds.

\section{Introduction}

The first aerosol indirect effect (Twomey, 1974) describes how, in the absence of changes in cloud macrophysical properties, increased aerosol concentrations lead to increased cloud albedo by increasing the droplet concentration $N_{d}$ and average droplet surface area. Secondary indirect effects encompass the changes to cloud macrophysical properties that occur in response to cloud microphysical changes. Most well-studied of these effects is a suppression of precipitation as $N_{d}$ increases (Albrecht, 1989), which can either enhance or offset the first indirect effect (Ackerman et al., 2004; Wood, 2007) by changing the moisture budget and entrainment rate. Other secondary effects include the influence of cloud droplet size upon condensation and evaporation rates (Wang et al., 2003; Xue and Feingold, 2006) and upon the entrainment rate through changes to the cloud droplet sedimentation flux (Bretherton et al., 2007). The combined effect

Published by Copernicus Publications on behalf of the European Geosciences Union. 
of the secondary indirect effects is highly uncertain regionally and globally (Lohmann and Feichter, 2005).

A number of satellite-based attempts to estimate the effects of aerosols on cloud macrophysical properties have been made using present-day correlations between aerosols and cloud properties (e.g. Kaufman et al., 2005; Quaas et al., 2008; Lebsock et al., 2008), but may be somewhat questionable due to covarying meteorological and aerosol impacts on clouds (e.g. Brenguier et al., 2003; Mauger and Norris, 2007; Stevens and Brenguier, 2009).

Model studies can control for meteorology but are limited by computing power, either by the need to parameterize small scale processes in larger scale climate models, or by a lack of generality for cloud resolving models. There is a need for better observational constraints for regional and global models. Models simulating aerosol indirect effects should be able to reproduce the mean cloud microphysical state and the temporal variability patterns of cloud microphysics associated with synoptic meteorological changes. Despite there being over a decade of suitable cloud microphysical retrievals (e.g. Han et al., 1994), their use by the large-scale modeling community beyond coarse-scale metrics such as land-ocean and Northern-Southern Hemisphere contrasts has been minimal. This reflects a paucity of diagnostic studies documenting spatial and temporal cloud microphysical variability that modelers can use, which may stem from outstanding concerns regarding retrieval accuracy. There has been only very limited assessment of the patterns of variability of cloud microphysical properties or indeed cloud properties other than cloud cover.

To fully understand the strength of aerosol impacts on clouds independent of meteorology, it is important to know the strength of meteorological impacts on clouds independent of aerosol changes (Stevens and Brenguier, 2009). Although it is not possible to determine this with observations alone, it is nonetheless useful to examine further how patterns of subseasonal meteorological variability relate to the cloud variability and albedo. This study investigates such variability in the southeast Pacific (SEP), a subtropical marine stratocumulus region.

The average albedo, $\alpha$, of a region is simply related to the top-of-atmosphere albedo of cloud and cloud fraction by the conventional relationship (Cess, 1976):

$\alpha=f_{c} \alpha_{\text {cld }}+\left(1-f_{c}\right) \alpha_{\text {clear }}$

where $f_{c}$ is the fraction of sky covered by low cloud, $\alpha_{\text {cld }}$ is the cloud albedo and $\alpha_{\text {clear }}$ the clear sky albedo. Over the ocean $\alpha_{\text {clear }}$ variability is weak compared with the other variables involved (Loeb and Kato, 2002) and we assume a constant value of 0.1 in accordance with satellite broadband radiometric observations (Bony et al., 1992). The cloud albedo $\alpha_{\text {cld }}$ is a function of optical depth, $\tau$, and the incident solar zenith angle, and $\tau$ is a function of cloud droplet concentration, $N_{d}$, and cloud liquid water path, $L_{p}$.
Given that clouds dominate albedo variability over the oceans, we can think of $N_{d}$ (a microphysical quantity), $L_{p}$, and $f_{c}$ (macrophysical quantities) as being the three fundamental contributors to albedo. The influence of these parameters on albedo variability has not been systematically explored. Here, we estimate their relative contributions to albedo variability over the SEP, a region with strong regional contrasts in cloud microphysical properties and persistent stratocumulus.

Stratocumulus clouds are susceptible to aerosols (Platnick and Twomey, 1994) and their relatively plane parallel nature allows their macrophysical and microphysical properties to be determined reasonably accurately using passive satellite remote sensing. Marine stratocumulus clouds continue to be difficult to simulate accurately in general circulation models (Zhang et al., 2005). Stratocumulus cloud regions therefore constitute a useful system in which to attempt microphysical variability characterization.

Previous studies have shown that on seasonal to interannual time scales, variations in low cloud amount are strongly correlated with variations in lower tropospheric stability (LTS), sea surface temperature, and atmospheric circulation (Klein and Hartmann, 1993; Norris and Leovy, 1994). On sub-seasonal timescales, correlations of low cloud amount with meteorological predictors are substantially weaker than on longer timescales, but LTS, relative humidity of the cloud layer, and cold advection do significantly correlate with variations in low cloud amount (Klein et al., 1995; Klein, 1997). Similar correlations exist with cloud liquid water path $\mathrm{Xu}$ et al., 2005), but variations in microwave-estimated liquid water path may largely reflect variations in cloud cover since microwave data do not allow separation into cloudy and clear contributions.

We investigate how changes in large scale meteorology, macrophysical and microphysical cloud properties are associated with changes in albedo, with a view toward providing useful constraints for regional and global models based on variability and to examine how cloud properties covary in a relatively simple regional system. We then use the results to hypothesize physical mechanisms that explain how meteorology impacts stratocumulus cloud variability, which could be tested with a model in future studies. Section 2 describes the data and methodology, and introduces the region of study. Section 3 investigates the contributions of the variance of cloud parameters to subseasonal albedo variance. Section 4 examines the relationship between large scale meteorology and cloud properties on subseasonal timescales. Section 5 discusses the findings and potential future work, and is followed by conclusions in Sect. 6 . 


\section{Data}

\subsection{Albedo proxy}

We use spatially averaged $1 \times 1^{\circ}$ daily MODIS Level 3 data (derived from Level 2 cloud retrieval data, King et al., 1997) from the NASA Terra satellite for the time period 2000-2008 to derive an approximate, once-daily proxy estimate of the albedo, $\alpha$. We investigate the dominant sources of subseasonal variability in this albedo estimate over the oceanic part of a spatial domain of $10-40^{\circ} \mathrm{S}$ and $70-100^{\circ} \mathrm{W}$.

To construct our albedo estimate, we begin with MODIS retrievals of effective radius, $r_{e}$, low cloud fraction $\left(f_{c}\right.$, the fraction of the sky covered by clouds with cloud top temperatures warmer than $273 \mathrm{~K}$ ), and cloud optical depth, $\tau$. The main cloud variables of interest, $L_{p}$ and $N_{d}$, are derived from the retrieved $\tau$ and $r_{e}$ assuming that the liquid water content increases linearly with height in the cloud layer (Szczodrak et al., 2001):

$N_{d}=K \tau^{1 / 2} r_{e}^{-5 / 2}$

$L_{p}=\frac{5}{9} \rho_{w} \tau r_{e}$

where $\rho_{w}$ is the density of liquid water and $K=1.125 \times 10^{-6} \mathrm{~cm}^{-1 / 2}$ is a weakly temperature and pressure-dependent thermodynamic constant (Bennartz, 2007), here estimated assuming a temperature of $280 \mathrm{~K}$ and a pressure of $900 \mathrm{hPa}$ appropriate for conditions at cloud level over the SEP.

We consider cloud droplet concentration, $N_{d}$, rather than $r_{e}$, as our fundamental cloud microphysical parameter, for three reasons: (a) droplet concentration is more fundamentally related to the underlying aerosol concentration than is the effective radius (e.g. Martin et al., 1994); (b) droplet concentration tends to be relatively constant with height in cloud whereas effective radius is strongly height dependent (e.g. Slingo et al., 1982); (c) for a given droplet concentration, the effective radius increases with increasing cloud liquid water, which causes undesirable "crosstalk" between the macrophysical variable $L_{p}$ and $r_{e}$ (Schuller et al., 2005).

We generate an albedo proxy from (1) by making direct use of the MODIS $f_{c}$ data, and by deriving $\alpha_{\text {cld }}$ from $\tau$ (MODIS), the incident solar zenith angle, the single scattering albedo $\left(\omega_{0}\right)$, and the asymmetry factor $(g)$, employing a simple radiative model. MODIS data are collected at a local time of roughly 10:30 a.m., so we estimate the albedo due to collimated incident radiation (while allowing the solar zenith angle to vary with latitude and day of year). We make the conservative scattering assumption $\left(\omega_{0}=1\right)$ so that $\alpha_{\text {cld }}$ solely depends on $\tau$ and the solar zenith angle, and not wavelength, ignoring solar absorption, since its impact on albedo is likely to be relatively small. We use a typical value of the asymmetry factor $g=0.85$ for scattering by liquid cloud droplets with negligible absorption at visible wavelengths

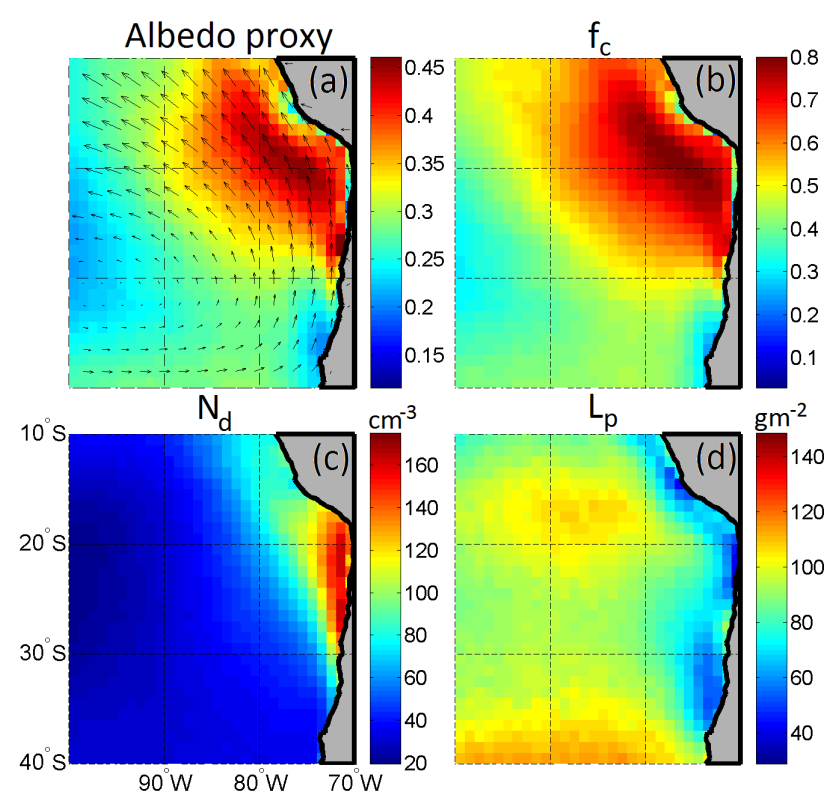

Fig. 1. 2000-2008 mean of (a) low cloud albedo proxy and controlling variables derived from MODIS data: (b) low cloud fraction $f_{c}$, (c) cloud droplet concentration $N_{d}$, and (d) cloud liquid water path $L_{p}$. Vectors in (a) are mean surface horizontal winds with maximum magnitude of $8 \mathrm{~m} \mathrm{~s}^{-1}$ in the longest arrows.

(Twohy et al., 2005). The cloud layer is assumed to be plane parallel. Even in relatively uniform stratocumulus clouds this assumption can introduce an albedo bias due to horizontally inhomogeneous $L_{p}$ (e.g. Cahalan et al., 1994), but we do not account for this here (see next paragraph). Based on Eq. (37) in King and Harshvardhan (1986), $\alpha_{\text {cld }}$ is calculated using the two-stream approximation via the delta-Eddington method for conservative scattering. This method is accurate to better than $5 \%$ for values of solar zenith angle less than $60^{\circ}$ and $\tau>0.9$, which encompasses most of the cloud retrievals in our dataset (the solar zenith angles at the time of the MODIS retrievals for our domain span $20^{\circ}-66^{\circ}$ and for only $0.3 \%$ of retrievals is $0<\tau<0.9$ ).

In the annual mean the albedo proxy (Fig. 1a) correlates strongly with daytime mean CERES albedo $(r=0.93)$, although the MODIS proxy corrected to a top of atmosphere (TOA) is on average $0.04(14 \%)$ higher than the CERES albedo. To correct to the TOA, we use the Fu-Liou radiative transfer model (Fu and Liou, 1992, 1993) applied to data from the EPIC Southeast Pacific stratocumulus cruise (Bretherton et al., 2004), to determine the effects of abovecloud absorption of solar radiation by water vapor and ozone, and above-cloud scattering. From this, an adjustment of the MODIS albedo proxy by a factor of $0.87 \pm 0.02$ is used to compare with the CERES TOA values. The value is not highly dependent upon water vapor path above the cloud, depending primarily on stratospheric ozone and cloud albedo (Thomas Ackerman, personal communication). Even after 
this correction, the MODIS derived TOA albedo estimates are still larger than the CERES albedo. This is because (a) MODIS Terra overestimates the daytime mean $f_{c}$ and $L_{p}$ because there are significant afternoon decreases in cloud cover and liquid water path in this region (Rozendaal et al., 1995; Wood et al., 2002); (b) we neglect the albedo bias associated with the sub- $1^{\circ}$ variability in cloud properties, which is estimated to be less than $7.5 \%$ for marine low clouds (Rossow et al., 2002. However, neither of these issues are likely to significantly impact the general findings in this study since we are herein concerned with variability rather than the mean albedo. The albedo proxy excludes high clouds, which aren't dominant in this region, but this may also contribute to some of the difference between the proxy and CERES values.

Daily mean meteorological conditions with $2.5 \times 2.5^{\circ}$ resolution are obtained from NCEP reanalysis data (Kalnay et al., 1996), including sea level pressure (SLP), horizontal wind $(\boldsymbol{V})$ at the surface and at $850 \mathrm{hPa}$ (above the marine boundary layer), omega $\left(\mathrm{Pa} \mathrm{s}^{-1}\right)$ at $850 \mathrm{hPa}$, and potential temperature $(\theta)$ at 1000 and $700 \mathrm{hPa}$. We derive temperature advection $\left(-V_{s f c} \cdot \nabla S S T\right)$ and lower tropospheric stability $\left(\mathrm{LTS}=\theta_{700 \mathrm{hPa}}-\theta_{1000 \mathrm{hPa}}\right.$, Klein and Hartmann, 1993) from these fields.

In addition, we use a once-daily estimate of the marine boundary layer (MBL) depth $z_{i}$ derived using the difference between Reynolds sea surface temperature and cloud top temperature (using the MODIS Terra L3 data at $1 \times 1^{\circ}$ discussed above). This employs the lapse rate formulation from Wood and Bretherton (2004), and makes the assumption that the top of the MBL is commensurate with the cloud top height, a good assumption for this region (Caldwell et al., 2005). Comparisons of this approach with radiosonde estimates of cloud top height in the region (Zuidema et al., 2009) show that the instantaneous uncertainty is better than $300 \mathrm{~m}$, consistent with error estimates from Wood and Bretherton (2004). Averaging over multiple days by compositing is expected to reduce this uncertainty.

A high-pass order 10 Butterworth filter with a cutoff frequency of $(31)^{-1}$ days is applied to all variables to remove variability in timescales longer than subseasonal, in particular the annual cycle. There is little power in all variables between 30 and 90 days (see Sect. 4.1), so the sub-seasonal and sub-monthly variability is very similar. Subseasonal power dominates the total albedo variability since power at less than 31 days constitutes over $80 \%$ of the total albedo power for most of the region. Along the Peruvian and extreme northern Chilean coast the seasonal cycle contributes more strongly (subseasonal power reduces to as low as $40 \%$ of the total), most likely reflecting the annual march of continental heating. The variables used to derive albedo show similar behavior.

\subsection{Region of study}

The largest and most persistent deck of subtropical marine stratocumulus clouds swathes the Southeast Pacific (SEP) off the coast of South America (Richter and Mechoso, 2004; Bretherton et al., 2004). A persistent subtropical high exists throughout the year centered near $30^{\circ} \mathrm{S}, 90^{\circ} \mathrm{W}$ which, together with the Andes, drives southerly flow along the South American coast. These winds cause upwelling of cold ocean water near the coast (Bretherton et al., 2004). Dry subsiding air associated with the high warms the air above the MBL, which can be entrained into the MBL, leading to cooling of the ocean surface by evaporation (e.g. Takahashi and Battisti, 2007). Hence the SEP is a region of cold sea surface temperatures and strong LTS harboring extensive marine stratocumulus year-round (Richter and Mechoso, 2004). Annual mean low cloud cover exceeds $60 \%$ over a large region and approaches $80 \%$ at the heart of the deck (Fig. 1b). The spatial pattern of mean cloud fraction, $f_{c}$, in the SEP is wellcorrelated with that in LTS as it is in other stratocumulus regions (e.g. Wood and Bretherton, 2006; Klein and Hartmann, 1993), consistent with strong meteorological controls on the mean cloud field.

Sources of anthropogenic aerosol precursors along the Chilean and Peruvian coasts, in contrast with very clean airmasses advected over the Pacific Ocean, make the SEP an attractive region in which to explore aerosol-cloud interactions. The pattern of mean cloud droplet concentration $N_{d}$ (Fig. 1c), largely reflects the spatial variation of accumulation mode aerosol concentration (Wood et al., 2008) and is evidence of strong continental or coastal aerosol sources. Copper smelters near the coasts of Chile and Peru are a major source of oxidized sulfur emissions, which in 1985 totaled about $1.5 \mathrm{TgS} \mathrm{yr}^{-1}$, similar to the total sulfur emissions from Mexico or Germany (Benkovitz et al., 1996). Natural emissions from volcanic and biogenic sources and DMS oxidation products from the ocean may also contribute to the concentration of cloud condensation nuclei. While the contribution from ocean sources is uncertain (e.g. Bates et al., 1992), the oceanic sulfur source is unlikely to be sufficient to explain the high droplet concentrations downwind of the smelters (Yang et al., 2009). The Andes act as a natural barrier to the dispersion of pollutants, and this, together with the relatively steady winds, might be expected to reduce the dimensionality of the aerosol/chemical transport problem in this region.

Before we embark on an examination of the temporal variability of the albedo and its contributing factors, we first explore how the time-mean albedo might be affected by the large spatial variation in time-mean droplet concentration. Figure 2 shows the impact of the spatial variations in mean $N_{d}$ shown in Fig. 1c on the mean albedo and the diurnal mean reflected solar flux. Interpreting this as the first aerosol indirect effect is only meaningful if one assumes that there are no cloud macrophysical responses to changes in $N_{d}$ (i.e. there 


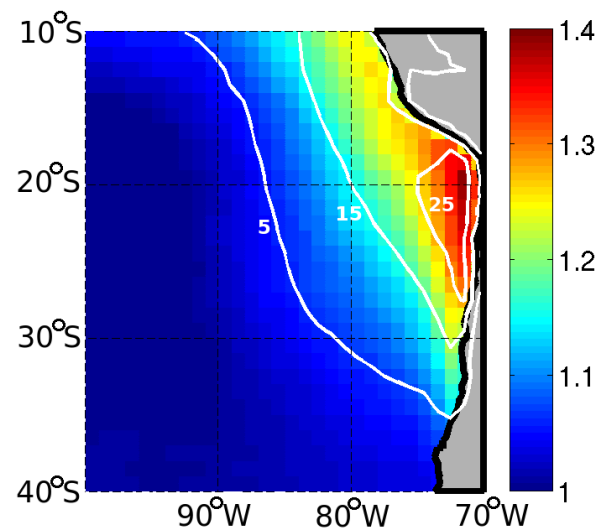

Fig. 2. The ratio of time-mean albedo calculated with the observed $N_{d}$ to the mean albedo calculated with the typical marine $N_{d}$ is shown by the colored contours. To calculate the denominator the observed $N_{d}$ over time at each point in space is replaced with the average time series of $N_{d}$ in a domain of $30-40^{\circ} \mathrm{S}, 90-100^{\circ} \mathrm{W}$, an area more "pristine" than near the coast providing a good representation of clean marine air. The white contour lines show the time mean of the difference between a diurnal mean estimate of the reflected solar flux and the same flux computed using the typical marine $N_{d}$. The numbers indicate $\mathrm{W} \mathrm{m}^{-2}$ of flux difference due to the different values for $N_{d}$.

are no second indirect effects beyond the Twomey effect) or changes in the meteorological forcing. In the absence of such changes, Fig. 2 shows that increasing the cloud droplet concentration from remote marine values to values found in the coastal strip would lead to albedo increases of as much as $20-40 \%$, or diurnal mean reflected solar flux increases of 15 $30 \mathrm{~W} \mathrm{~m}^{-2}$.

There is a degree of spatial correlation of the patterns of mean $N_{d}$ with both $f_{c}$ and the cloud liquid water path $L_{p}$ north of $30^{\circ} \mathrm{S}$ within $5-10^{\circ}$ of the coast (Fig. 1). These spatial correlations do not imply causality, but it seems reasonable to suppose that the time-mean pattern of $N_{d}$ is affected by the same large scale meteorological processes (i.e. the advection of continentally-influenced airmasses and associated pollutants by the mean winds over the SEP) which also influence cloud cover and liquid water path. Such convolution of the meteorological and aerosol influences on cloud macrophysics makes it difficult to quantify aerosol indirect effects from the mean fields alone despite attempts in the literature to do this (Kaufman et al., 2005).

\section{Factors influencing the albedo variance}

In this section we explore the contributions to the temporal and spatial variability in the albedo from the three fundamental controlling variables $f_{c}, N_{d}$, and $L_{p}$ using an equation for the variance of albedo dependent on the variances of the controlling variables.

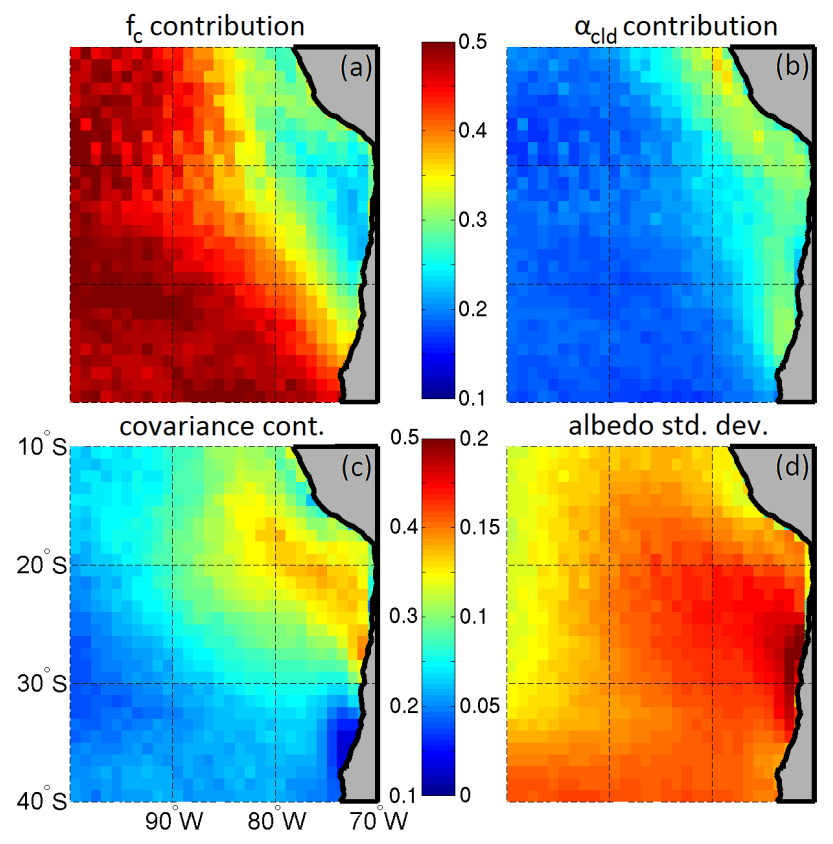

Fig. 3. Relative fractional contribution of terms in Eq. (5) to albedo time variance. The panels show the contributions from the first, second and third terms in the equation, and because the squared coefficients of variation of $f_{c}$ and $\alpha_{\text {cld }}$ are small $\left(\left(\frac{\sigma_{x}}{\bar{x}}\right)^{2}<1\right.$, see Appendix A), the terms represent contributions from (a) $f_{c}$ variance, (b) $\alpha_{\text {cld }}$ variance, and (c) the covariance between $f_{c}$ and $\alpha_{\text {cld }}$ to albedo variance. These are all computed by dividing the corresponding terms by the sum of the absolute value of all terms. 4th order terms are not shown because their relative contribution is smaller ( $\sim 6-10 \%)$ over most of the domain (up to $21 \%$ in small localized regions south of $\left.30^{\circ} \mathrm{S}\right)$. (d) is the albedo standard deviation.

\subsection{Albedo variance}

We can rewrite our albedo proxy (Eq. 1) as

$\alpha=f_{c}\left(\alpha_{\text {cld }}-\alpha_{\text {clear }}\right)+\alpha_{\text {clear }}$.

Because we assume constant $\alpha_{\text {clear }}$, Eq. (4) is a simple product of two variables, $f_{c}$ and $\alpha_{\text {cld }}-\alpha_{\text {clear }}$. By redefining each variable $x$ as a sum of a mean $\bar{x}$ and a perturbation value $x^{\prime}$, the terms can be rearranged (see Appendix A) to obtain an expression for the albedo variance:

$$
\begin{array}{r}
\sigma_{\alpha}^{2}=\overline{\alpha^{\prime 2}}=\overline{\left(\alpha_{\text {cld }}-\alpha_{\text {clear }}\right)^{2} f_{c}^{\prime 2}}+\overline{\alpha_{\text {cld }}^{\prime 2} f_{c}^{2}}+ \\
2 \overline{f_{c}}\left(\overline{\alpha_{\text {cld }}}-\alpha_{\text {clear }} \overline{\alpha_{\text {cld }}^{\prime} f_{c}^{\prime}}+\left[-\overline{\alpha_{\text {cld }}^{\prime 2} f_{c}^{\prime 2}}-\left(\overline{\alpha_{\text {cld }}^{\prime} f_{c}^{\prime}}\right)^{2}\right]\right.
\end{array}
$$

\subsection{Application to temporal variability}

The subseasonal albedo variability (Fig. 3d) maximizes about five degrees upwind (see Fig. 1a for mean surface 


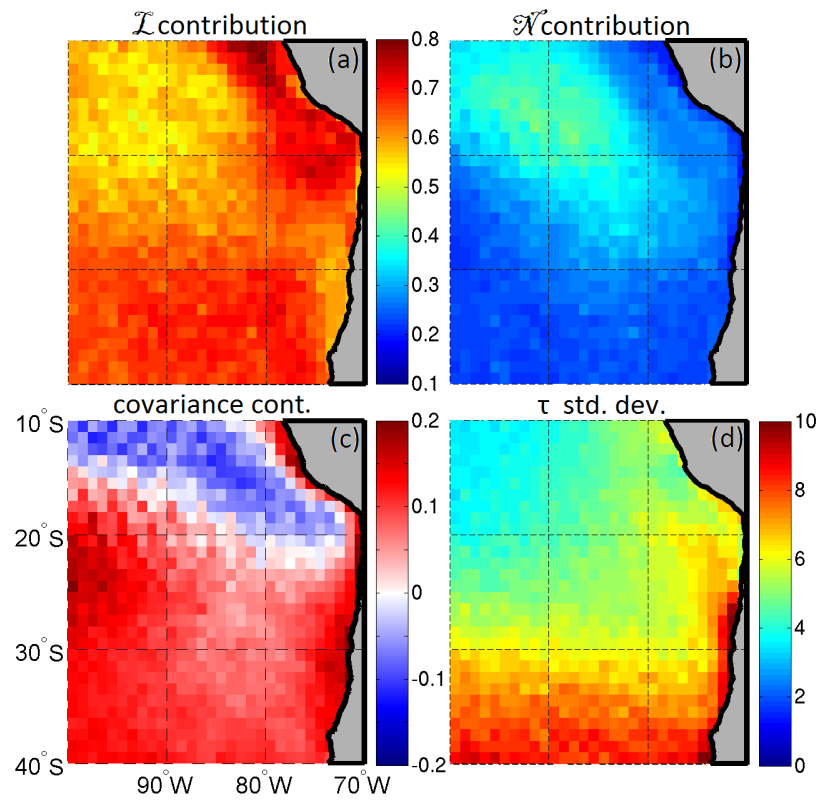

Fig. 4. Relative fractional contributions of defining terms to $\tau$ time variance based on Eqs. (5) and (6). The squared coefficients of variation for $\mathcal{N}$ and $\mathcal{L}$ are small $\left(\left(\frac{\sigma_{x}}{\bar{x}}\right)^{2}<1\right.$, see Appendix $)$. The panels show the relative contributions from (a) $\mathcal{L}$ variance, (b) $\mathcal{N}$ variance, and (c) the covariance between $\mathcal{N}$ and $\mathcal{L}$, all computed by dividing the corresponding terms by the sum of the absolute value of all terms. 4th order terms (not shown) were negligible $(<6 \%)$. (d) is the $\tau$ standard deviation.

winds) of the maximum mean cloud cover (Fig. 1b). Figure 3 shows contributions from each of the terms to the temporal $\sigma_{\alpha}^{2}$ at different locations throughout the domain. Far from the coast $f_{c}$ variance dominates albedo variance, but in the region of maximal mean cloud cover (about $10-30^{\circ} \mathrm{S}$, $70-90^{\circ} \mathrm{W}$, Fig. 1b) and about 2-3 degrees upwind of this maximum its contribution is weaker, which makes intuitive sense, since one would expect $\sigma_{f_{c}}^{2}$ to be smaller in regions that are more consistently cloudy. This reduced contribution from $f_{c}$ variance is compensated for by $\alpha_{\text {cld }}$ variance, and, particularly on the western side of the maximum in $f_{c}$, by the covariance of $\alpha_{\text {cld }}$ with $f_{c}$. The covariance is positive because for times when clouds have greater cover their liquid water path is also greater. The fourth order terms in Eq. (5) contribute 6-10\% over most of the domain, and so are generally weaker contributors to albedo variance, but their nonnegligibility suggests a relatively high level of complexity in the covariability of cloud cover and cloud albedo. These four terms completely explain the variance in albedo, and thus provide a useful tool for distinguishing the impacts of the variances of the defining variables.

A similar analysis is applied to the cloud optical thickness $\tau$, which almost uniquely ${ }^{1}$ determines $\alpha_{\text {cld }}$. Rearrang-

\footnotetext{
${ }^{1}$ It was found that variations in solar zenith angle contributed
}

Table 1. Fractional contributions to albedo spatial variance (20002008 time series). The mean, and the 90th and 10th percentiles of the distribution of daily contributions to spatial variance from each variable are shown. The $L_{p}$ and $N_{d}$ spatial variance contributions to albedo variance are computed by multiplying their contributions to $\tau$ spatial variance by the contribution of $\alpha_{\text {cld }}$ to albedo spatial variance.

\begin{tabular}{cccccc}
\hline & $f_{c}$ & $\operatorname{Cov}\left(\mathrm{f}_{c}, \alpha_{\text {cld }}\right)$ & $\alpha_{\text {cld }}$ & $L_{p}$ & $N_{d}$ \\
\hline $90 \%$ & 0.52 & 0.31 & 0.23 & 0.16 & 0.079 \\
Mean & 0.43 & 0.25 & 0.19 & 0.11 & 0.047 \\
$10 \%$ & 0.36 & 0.19 & 0.15 & 0.076 & 0.021 \\
\hline
\end{tabular}

ing Eqs. (2) and (3), we can write

$\tau=C \mathcal{N} \mathcal{L}$

where $C=\left[\frac{9}{5} \frac{1}{\rho_{w} K^{2 / 5}}\right]^{5 / 6}=0.2303 \mathrm{~m}^{8 / 3} \mathrm{~kg}^{-5 / 6}$ is effectively a constant (Wood and Hartmann, 2006), $\mathcal{N}=N_{d}^{1 / 3}$, and $\mathcal{L}=L_{p}^{5 / 6}$. This allows us to treat the analysis of $\tau$ variance as a product in the same way as we did for $f_{c}$ and $\alpha_{\text {cld }}$ contributions to overall albedo. We see from Fig. 4 that $\mathcal{L}$ dominates the $\alpha_{\text {cld }}$ variability throughout the domain, although $\mathcal{N}$ makes a significant contribution in the northwest quadrant of the domain, explaining up to $40 \%$ of the $\tau$ variance. However, the region where the variance of $\mathcal{N}$ contributes most is where the variance of $f_{c}$, rather than that of $\alpha_{\text {cld }}$ dominates the variance of albedo. A multiplication of the contributions of $\mathcal{N}$ to $\tau$ (Fig. 4b) by the contribution of $\alpha_{\text {cld }}$ to albedo (Fig. 3b) gives a rough idea of how much $\mathcal{N}$ contributes to albedo (Fig. 5). Interestingly, the contribution of $\mathcal{N}$ variance to overall albedo is strongest downwind of aerosol sources, but the contribution is very small $(<10 \%)$ throughout the entire domain. Insofar as variations in $\mathcal{N}$ reflect underlying aerosol variability, this suggests that it is difficult to separate meteorological and aerosol impacts on the albedo using temporal variability since the albedo variability is swamped by variability in cloud fraction and liquid water path. The covariance between $\mathcal{N}$ and $\mathcal{L}$ constitutes a relatively small contribution to $\tau$ (Fig. 4c), can be either positive or negative depending upon location, and is very similar to the direct correlation between $N_{d}$ and $L_{p}$ (not shown).

\subsection{Application to spatial variability}

The same procedure can be applied to the variance in albedo over space. On each day the spatial variance of the $1 \times 1$ degree albedo estimates over the domain is derived, as well as fractional contributions from the albedo-controlling variables. We then have time series of fractional contributions

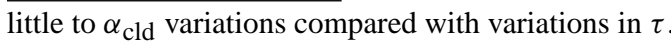


of each variable's spatial variance to the albedo spatial variance on each day. The controlling variables contribute to the albedo spatial variance in a similar manner as they did for time variance. Cloud fraction is the largest contributor on $97 \%$ of the days, explaining on average $43 \%$ of the albedo spatial variance (Table 1). Covariance of $\alpha_{\text {cld }}$ with $f_{c}$ is the second largest contributor followed by $\alpha_{\text {cld }}$. As is the case for temporal variance, the spatial variance of $N_{d}$ rarely explains more than $10 \%$ of the albedo spatial variance. The domain mean fractional increase in albedo associated with the mean pattern of $N_{d}$ (Fig. 2) is 12\%, so this is consistent. Thus both the temporal and spatial variability contributions of $N_{d}$ to albedo variability are somewhat small compared with variations in other cloud parameters, emphasizing the challenge that we face in detecting relatively small aerosol indirect effects on albedo above the meteorological noise.

It is interesting that although the mean (Fig. 1c) and variance (not shown) of $N_{d}$ are high near the coast, the $N_{d}$ variance contribution to albedo variance is fairly weak. This is partially due to the $1 / 3$ power dependence of albedo on $N_{d}$, but is also indicative that even large excursions in cloud droplet concentration can be overwhelmed by the variations in cloud liquid water path and cloud cover that also occur in the coastally influenced region. We should note that nonlinear and time lagged relationships between $N_{d}$ and the other cloud variables involved are not captured in this analysis, so it is possible that the full impact of high droplet concentrations on the albedo is not realized locally. For example, if a parcel of air experiences an injection of aerosols and forms cloud, then advects, this analysis will not capture how changes in $N_{d}$ in one location affect the albedo further downwind, after the aerosol has had time to affect the macrophysical cloud fields. Also, large scale meteorological influences known to play a role in cloud variability (e.g. stability, temperature advection, winds, and subsidence associated with the subtropical high) could simultaneously influence both cloud macrophysical and cloud microphysical properties. It is thus clear that investigation of the meteorological influence is necessary.

\section{Meteorological influence}

We expect that both macrophysical and microphysical properties of clouds will be influenced by large scale meteorology, and indeed it has been known for some time that macrophysical properties of subtropical marine stratocumuli experience such influence (Klein et al., 1995; Klein 1997; Xu et al., 2005). There is some limited evidence that subtropical marine stratocumulus cloud microphysical properties are also modulated by changes to the large scale meteorology (e.g. Wood et al., 2008), but no systematic studies of the meteorological impacts on cloud microphysical variability on the regional scale currently exist. To what extent large scale meteorological forcing drives changes in cloud variables, and

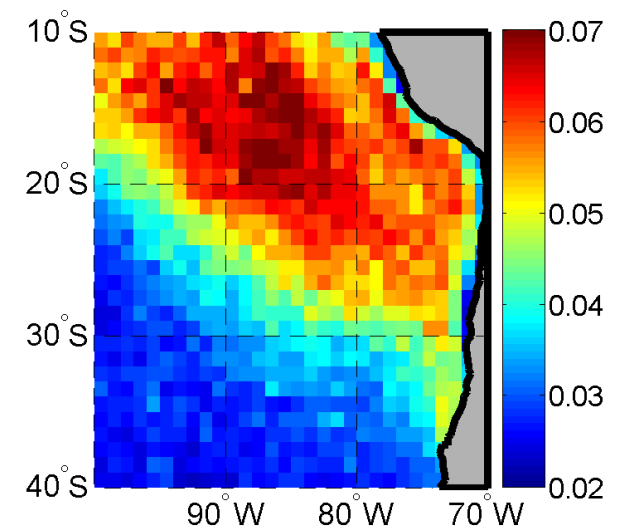

Fig. 5. Fractional contribution of $\mathcal{N}$, or essentially $N_{d}$, to albedo variance approximated by multiplying the contribution of $\mathcal{N}$ to $\tau$ variance (Fig. 4b) by the contribution of $\alpha_{\text {cld }}$ to albedo variance (Fig. 3b).

thus albedo, as opposed to small scale and aerosol driven internal feedback processes, is a question that cannot be answered with observational analysis alone. However, it is useful to investigate the relationships between observations of sea level pressure, SLP (considering it the most fundamental indicator of large scale meteorology in the lower troposphere) and cloud properties to gain some insight as to the degree to which the variability of cloud properties, identified using the fraction of variance approach, is associated with patterns of large scale meteorological variability.

\subsection{Large scale synoptic variability in the SEP}

In this section we describe the dominant modes of SLP variability, which essentially represent changes to the subtropical high. We apply Empirical Orthogonal Function (EOF) analysis to daily mean SLP fields (a good introduction to EOF analysis can be found in Wilks, 2006). The EOF spatial pattern that explains the maximal amount of variance of SLP possible is referred to as EOF1. Its corresponding principal component (PC1) is the temporal structure that represents the magnitude of EOF1 in the data over time. The annual cycle in SLP is removed in the same way as for the cloud data. The dominant mode (EOF1) of sub-seasonal variability in SLP in the domain $10-40^{\circ} \mathrm{S}, 70-100^{\circ} \mathrm{W}$ explains 60 $70 \%$ of the total SLP variance (Fig. 6a), and does not overlap with other modes determined using the North et al. criteria (1982) with the Bretherton et al. (1999) method for computing degrees of freedom. PC1 has maximum subseasonal power in periods of 10-20 days (Fig. 6b), and this is insensitive to the choice of filter frequency in the range 30-90 days demonstrating weak intraseasonal meteorological variability. Lag analysis (not shown) and the strong correlation $(r=0.95)$ of PC1 with a time series of average SLP in a small box around the mean subtropical high location $\left(30^{\circ} \mathrm{S}, 90^{\circ} \mathrm{W}\right)$ 

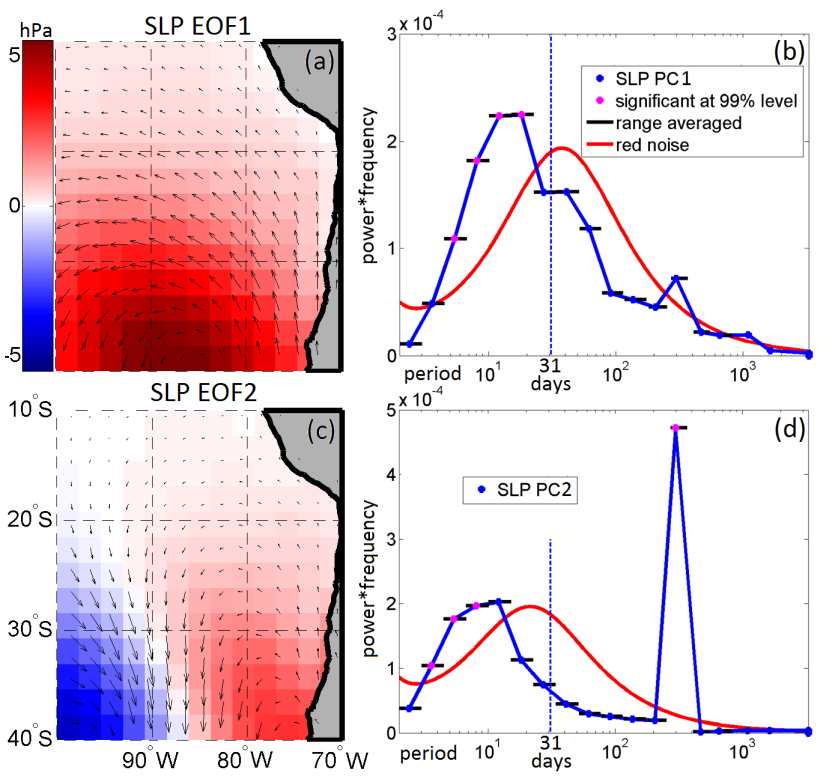

Fig. 6. Dominant EOF/PC's of SLP data. Data are weighted by the square root of the cosine of the latitude so that equal areas receive equal variance weighting independent of latitude. (a) is the spatial EOF1 pattern of filtered SLP data, and the units are the amplitude of SLP associated with a 1 standard deviation variation of PC1. Vectors represent composite difference (see Sect. 4.2.1) surface winds, longest vectors are $5 \mathrm{~m} \mathrm{~s}^{-1}$. (b) is the power spectrum of $\mathrm{PC} 1$ of the unfiltered SLP data (for all analysis the filtered PC1 is used). 31 days is the cutoff period for the filter. "Range averaged" indicates the range of periods averaged to get each point. The "red noise" spectrum is the null hypothesis for the significance of each point, computed using the autocorrelation of the $\mathrm{PC}$ at a lag of 1 day. (c) is the EOF2 pattern presented in the same manner as (a) and (d) the power spectra of PC2 of unfiltered SLP data.

indicates that this dominant mode represents a strengthening and weakening of the subtropical high. Midlatitude and other types of moving and stationary waves centered to the south of our domain modulate the strength of the high (e.g. Garreaud, 2001), producing large scale meteorological changes we investigate using the $\mathrm{PC} 1$ as an index for the subtropical high strength. The second principal component (PC2) of SLP explains about $20 \%$ of the variance in SLP and captures some modulation of the subtropical high by eastward propagating midlatitude waves (Fig. 6c, d). Lag analysis (not shown) indicates a positive SLP anomaly moving eastward slightly faster (about $8-10^{\circ}$ longitude per day) than seen in PC1 (about $6-8^{\circ}$ longitude per day). The maximum power in PC2 is at slightly shorter periods than PC1, peaking significantly above an equivalent red noise spectrum at periods of 5-12 days (Fig. 6d).

Although by definition PC2 is uncorrelated with PC1, it is lag-correlated. The PC2 most strongly correlates with PC1 [+2] (correlation coefficient $r=0.45$ ), meaning that there is a tendency for high pressure at $75-80^{\circ} \mathrm{W}$ two days fol- lowing high pressure at $85-90^{\circ} \mathrm{W}$. Thus, some part of PC2 also captures the eastward propagation of midlatitude waves. However, some part of PC2 variability is independent of that in PC1 and together their behavior can be described more appropriately as reflecting changes in the shape and zonal extent of the subtropical high as opposed to just its strength (examples of such distortions to the shape of the subtropical high are shown in Garreaud et al., 2001). Large values of PC2 reflect high pressure close to the Chilean coast (Fig. 6c) and so PC2 might be tied more strongly than PC1 to atmosphereland interactions in the coastal zone, such as the formation of coastal lows due to flow blocking by the southern Andes range (we will return to this in Sect. 4.3.2). Together PC1 and PC2 explain $80-90 \%$ of the subseasonal variance in SLP over the region.

\subsection{Response of cloud variables to large scale SLP variability}

\subsubsection{Composites of cloud variables on SLP PC1}

To understand how cloud and meteorological variables covary with the meteorological changes associated with the subtropical high, we will composite them on SLP PC1 and PC2 time series. A "composite difference" of a variable $X$ on a time series $T$ is generated by differencing the mean fields of $X$ formed on those days with strong positive and strong negative values of $T$ (with strong here indicating that the magnitude of the time series is greater than one standard deviation away from its mean, and negative and positive referring to the sign of the anomalies about the mean). In the cases where a "fractional composite difference" is shown, these composite differences are then divided by the time-mean $X$ field. A "composite difference of $X$ on $T[+n]$ " represents the same differencing of mean fields of $X$, but on $n$ days after strong magnitude days in $T$.

Patterns of subseasonal variability in albedo, $N_{d}$ and $L_{p}$ associated with the dominant mode of SLP variability are formed using fractional composite differences on SLP PC1 (Fig. 7a).The pattern of the $f_{c}$ is almost identical qualitatively to the albedo pattern and thus is not shown. It is clear that significant large-scale changes in all cloud variables contributing to albedo are associated with modulation of the subtropical high strength and these changes can be a significant fraction of the mean values. Composite differences in $f_{c}$ and $L_{p}$ reach $25-30 \%$ of their mean values, while $N_{d}$ differences are as high as $50 \%$ in some regions. Droplet concentration variance still does not contribute strongly to the albedo variance (Sect. 3) despite this significant modulation, in part because of simultaneous meteorologically-driven variations in other parameters such as $L_{p}$ and $f_{c}$ (Fig. 7a, c, e). This makes it difficult to attribute observed albedo changes to the Twomey effect or to other aerosol-cloud interactions.

Fractional composite differences on PC1[+3] (Fig. 7b, d, e) show us the time evolution of the responses to the SLP. 


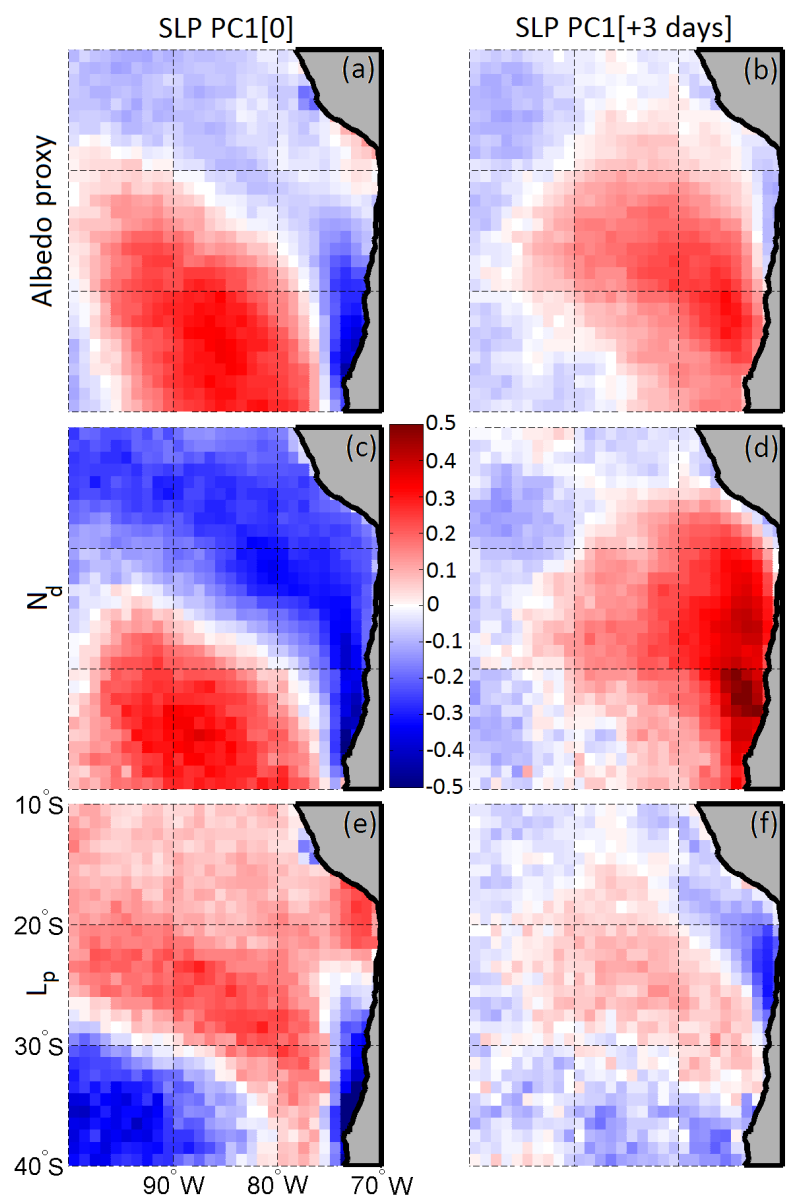

Fig. 7. Fractional composite differences on (a), (c), (e) SLP PC1[0] and (b), (d), (f) SLP PC1[+3], 3 days after strong values in SLP PC1. Composites are generated as described in Sect. 4.2.1.

A lag of 3 days was chosen because the strongest positive anomalies of albedo, $N_{d}$, and $f_{c}$ in the region of maximal mean stratocumulus generally occur 2-3 days after maxima in PC1. This is likely partly due to advection of the SLP signal by the anticyclonic near-surface winds (Fig. 1a) which have a typical magnitude of $5 \mathrm{~m} \mathrm{~s}^{-1}$ (e.g. Fig. 9 shows a positive $N_{d}$ anomaly moving about 4-5 degrees per day). This lagged response of the stratocumulus cloud properties is somewhat consistent with $\mathrm{Xu}$ et al. (2005) who found changes in cloud macrophysical parameters lagging changes in SLP by 1-2 days. Besides differences in methodology and variables examined, they used a domain $\left(10-25^{\circ} \mathrm{S}, 80\right.$ $100^{\circ} \mathrm{W}$ ) that did not include the easternmost $10^{\circ}$ of the domain we are considering, so it makes sense that their domain would see the signal of SLP a day earlier than ours. Also, PC2 represents positive SLP anomalies closer to the coast (Fig. 6c), and the positive $N_{d}$ anomaly composited on this index reaches the coastal regions 1-2 days after PC2 maxima (Fig. 9), indicating a consistent response time of a cloud variable to changes in SLP upwind.
Figure 7 shows the patterns of anomalies of $N_{d}$ and albedo (and thus also $f_{c}$ ) composited on SLP PC1 are positively correlated. We caution interpretation of this as an aerosol indirect effect because we saw earlier that $N_{d}$ itself does not contribute strongly to albedo variability (Fig. 4 ) and because composite patterns of both $N_{d}$ and albedo are clearly associated with meteorological changes. However, this does not rule out aerosol-cloud interaction in driving cloud cover changes. A useful null hypothesis to test with a regional model is that meteorology dominates changes in both $N_{d}$ and $f_{c}$.

Liquid water path anomalies do not evolve in the same way as those of the other variables: the signal does not appear to propagate eastward significantly, although the coastal negative anomaly does move northward (Fig. 7). Three days after strong values in PC1 the $L_{p}$ anomalies are substantially weaker than they are on the days of strong subtropical high anomalies. This may be because there are active negative feedbacks like drizzle and entrainment that limit the possible variability in $L_{p}$. Another interesting feature of Fig. 7 is that in much of the domain $L_{p}$ is negatively correlated with $N_{d}$. That is, on days when the subtropical high is stronger, $L_{p}$ tends to be larger in regions where $N_{d}$ is smaller and vice versa, opposite of one would expect from the Albrecht hypothesis. However, $L_{p}$ and $N_{d}$ variations associated with SLP changes are positively correlated in a strip along the coast from about $25^{\circ} \mathrm{S}$ to $40^{\circ} \mathrm{S}$ on days of strong PC1[0], indicating regional differences in the physical mechanisms by which $L_{p}$ and $N_{d}$ vary simultaneously with each other (also seen in Fig. 4c) and meteorology. Previous studies (Twohy et al., 2005; Matheson et al., 2005) have found negative correlations between aerosol or cloud droplet concentration and liquid water path in other regions of subtropical marine stratocumulus. It is possible that meteorology is playing a role in driving covariability in these regions through nonlinear processes and lagged influence, though simple linear regression analysis indicate that the meteorological component of the covariance between $L_{p}$ and $N_{d}$ (correlation coefficient ranging -0.3 to 0.3 throughout the domain, with same spatial pattern as Fig. 4c) is small.

These results are not strongly dependent on season. For example, the fractional composite difference pattern of albedo on the PC1 from EOF analysis performed on SLP data during September through November (Fig. 8), the season of peak cloud cover and albedo, looks remarkably similar to the equivalent year-round pattern (Fig. 7a). Other cloud variables behave similarly. Thus, the meteorological relationships observed are not limited to a particular season.

\subsubsection{Meteorological influence on dominant modes of cloud variability}

We also apply EOF analysis directly to the cloud variables (over a subdomain of the maximal mean cloud cover, 10$30^{\circ} \mathrm{S}, 70-90^{\circ} \mathrm{W}$, to capture stratocumulus variability) and 


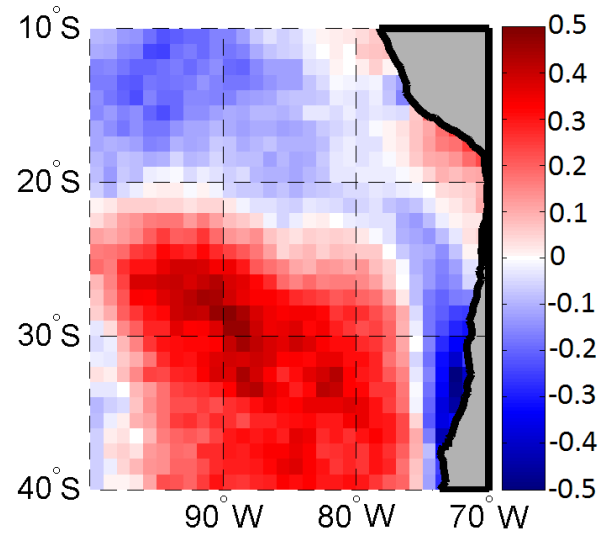

Fig. 8. Fractional composite difference of albedo on the dominant principal component of SLP during a season: September-OctoberNovember, 2000-2008. Compare with Fig. 7a.

find dominant patterns of cloud variability qualitatively similar to the composite differences of cloud variables on SLP $\mathrm{PC} 1$ [+3], with maximal positive anomalies in $f_{c}$ and albedo seen in the region of peak cloud cover, and maximal anomalies in $N_{d}$ near the coast. The PC1's of albedo, $f_{c}$, and $N_{d}$ have peak power in periods near 10 days, consistent with the peak power in SLP. Compositing SLP on a cloud variable $\mathrm{PC} 1$ (such as $f_{c}$ ) shows, as expected, a maximal high pressure anomaly three days before maximal values in the cloud variable PC1. Consistently, the PC1's of albedo, $f_{c}$, and $N_{d}$ correlate significantly ( $99 \%$ confidence level) with the SLP PC1 $[+3]$ with maximum correlation coefficients of $0.2-0.3$, and even better with the SLP PC2[+2]. The correlation coefficient between SLP PC2[+2] and either albedo $\mathrm{PC} 1$ or $f_{c} \mathrm{PC} 1$ is in the range $0.3-0.4$, and the correlation coefficient between SLP PC2[+2] and $N_{d}$ PC1 is approximately 0.5 . This indicates that SLP PC2 is important for cloud variability despite explaining only $20 \%$ of SLP variability. This evidence helps to confirm that the subtropical high is an important driver of the dominant modes of largescale variability of the cloud parameters, especially the cloud droplet concentration. In addition, the PC1's of albedo, $f_{c}$, and $N_{d}$ correlate strongly with each other (correlation coefficients ranging from 0.6 to 0.9 ), indicating that these dominant modes of cloud variability likely reflect similar physical mechanisms due to large scale meteorological influence.

The first EOF/PCs of cloud parameters tend to explain only $10-30 \%$ of the variance in these parameters because the cloud data both is higher resolution and has higher spatial variability at small scales than SLP. The latter effectively constitutes a source of small-scale noise in our analysis that is likely to be uncorrelated with the large scale influences, and is particularly acute for cloud liquid water path (Table 2). SLP is clearly not the only controlling variable for stratocumulus clouds, and other meteorological processes, many of which may be independent of SLP changes, may play a role
Table 2. Ratio of the time mean of the spatial variance of each variable at a $1^{\circ} \times 1^{\circ}$ grid resolution compared with that using a $2^{\circ} \times 2^{\circ}$ grid resolution.

\begin{tabular}{cccccc}
\hline$L_{p}$ & $\alpha_{\text {cld }}$ & $N_{d}$ & $\alpha$ & $f_{c}$ & $z_{i}$ \\
\hline 1.60 & 1.46 & 1.27 & 1.23 & 1.22 & 1.09 \\
\hline
\end{tabular}

in controlling clouds. However, no single meteorological predictor was found to be better connected to the cloud variability than SLP. We cannot distinguish between meteorological forcing and aerosol indirect effects using SLP alone, but we can use the magnitude of the responses of cloud variables to the SLP PC1 and PC2 as an observational constraint to evaluate models.

Liquid water path complicates attempts at simple physical interpretation of findings. Of the parameters considered, $L_{p}$ is the most variable on spatial scales comparable with the data resolution. Liquid water path shows the greatest loss of variance when averaged over $2 \times 2^{\circ}$ compared with the standard $1 \times 1^{\circ}$ (Table 2), has the smallest amount of variance explained by its first EOF/PC ( $9 \%)$, and has the weakest lagged signal composited on other PC1s (as seen on the SLP PC1 in Fig. 7b). The power spectra of the $L_{p}$ PC1 peaks at period of 6-8 days while the other variable's PC1s peak closer to 10 day periods (not shown). Liquid water path variability dominates $\alpha_{\text {cld }}$ variability in time (Fig. 4a) and space (as seen by the ratio of $\alpha_{\mathrm{cld}}$ spatial variance at higher versus lower resolutions, Table 2), and thus $\alpha_{\text {cld }}$ also deviates from the behaviors of the relationship between SLP and cloud variables albedo, $f_{c}$, and $N_{d}$. The small-scale $L_{p}$ variability is likely more strongly influenced by mesoscale cellular convection (Wood and Hartmann, 2006) than are the other cloud variables. We note that this small-scale variability adds an additional complication to the separation of meteorological and aerosol effects.

\subsection{Dominant mechanisms determining cloud response to SLP variability}

In this section, we combine evidence obtained by compositing a variety of cloud and meteorological variables on the dominant modes of SLP variability, to examine and develop hypotheses explaining the influence of meteorology on both cloud macrophysics and microphysics.

\subsubsection{The influence of cold advection and stability}

Compositing meteorological variables on the SLP PC1 is useful for investigating the driving large scale meteorological processes associated with variability in the strength of the subtropical high. Temperature advection and stability (LTS) correlate significantly with stratocumulus cloud cover (Xu et al., 2005; Klein 1997), and we see that a strong high 


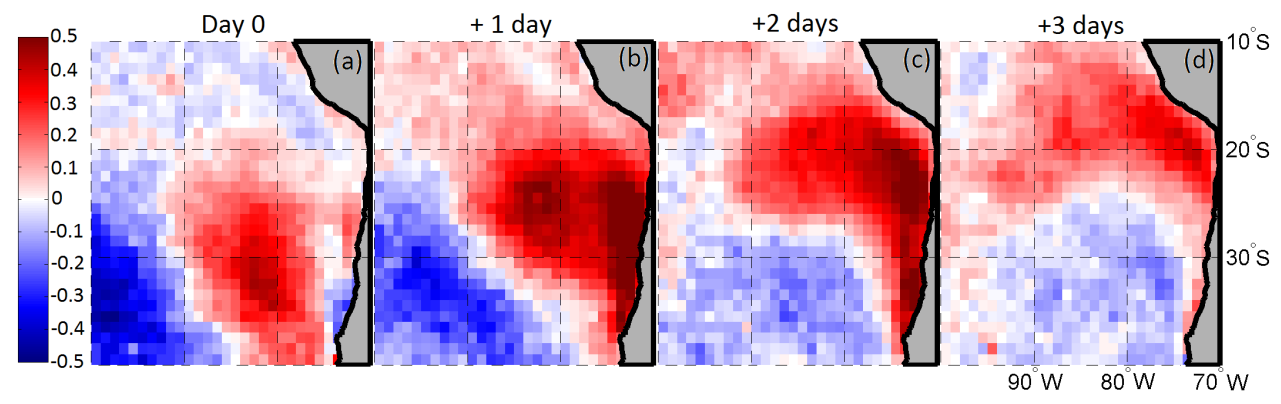

Fig. 9. (a) Fractional composite difference of $N_{d}$ on SLP PC2. (b)-(d) are $N_{d}$ composite differences on 1-3 days after strong values in SLP PC2.

induces stronger cold advection (Fig. 10a) caused in part by increased surface wind speed (Fig. 6a). The cold advection increases surface latent and sensible heat fluxes, causing a destabilization of the MBL, stronger overturning and moisture transport into the cloud layer, and thicker clouds (Xu et al., 2005). At the same time, enhanced subsidence to the east of the strong high (Fig. 10c) suppresses the growth of the MBL which may help explain why fractional $L_{p}$ composite differences are weaker than those in $f_{c}$ (Fig. 7). The MBL to the east of the high pressure anomaly cools while enhanced subsidence warms the free-troposphere, increasing the LTS (which maximizes roughly two days after the peak SLP PC1, as shown in Fig. 10c), allowing for a shallower, more strongly capped MBL and more extensive cloud cover, consistent with Klein (1997). The anomaly in $f_{c}$ persists and advects northward with the mean flow to resemble the albedo response in Fig. $7 \mathrm{~b}$.

While this mechanism is consistent with the cloud cover behavior in the southern two thirds of our domain, to the north of $20^{\circ} \mathrm{S}$ and in the near-coast region the cloud cover anomalies appear to be more difficult to explain. The mechanism also does not explain the negative anomalies of albedo and $N_{d}$ composited on SLP PC1[0] nor the enhancement of the positive $N_{d}$ anomaly on PC1[+3] (Fig. 7d). We turn to SLP PC2 to understand the $N_{d}$ anomalies.

\subsubsection{A conceptual model for cloud droplet concentration variability}

Composite differences of cloud and meteorological variables on the SLP PC2 suggest that it is not just the strengthening and weakening of the subtropical high that is important for how large scale meteorology affects cloud properties, but also its location. We expect near-coastal anomalies in the subtropical high to have a stronger influence on the coastal meteorology than anomalies further offshore. Evidence that this is the case was presented in Sect. 4.2.2 showing that there are stronger correlations of the dominant cloud macrophysical variability patterns with SLP PC2 than with SLP PC1. There is also a somewhat stronger $N_{d}$ anomaly in the

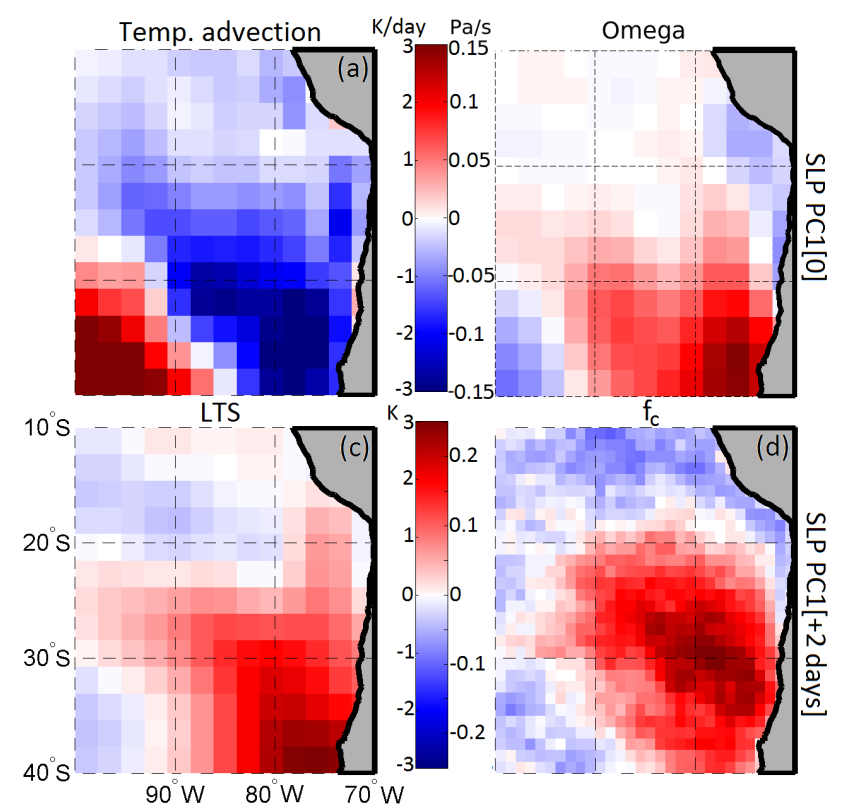

Fig. 10. Composite differences (not fractional) of (a) temperature advection on SLP PC1[0], (b) omega $\left(\mathrm{Pa} \mathrm{s}^{-1}\right)$ at $850 \mathrm{hPa}$ on SLP PC1[0] (red indicating strong subsidence), (c) LTS on SLP $\mathrm{PC} 1[+2]$, and $(\mathbf{d}) f_{c}$ on SLP PC1 $[+2]$.

coastal zone associated with SLP PC2 (Fig. 9) than with PC1 (Fig. 7b).

Although composite difference patterns of cloud fraction and most meteorological variables on SLP PC2 are somewhat similar to those two days after maxima in SLP PC1 $(\mathrm{PC} 1[+2])$, there are notable differences in the patterns of $L_{p}$, with a much stronger signal in $L_{p}$ on PC2 (Fig. 11a, c). This is particularly notable between $30-40^{\circ} \mathrm{S}$ in a region extending from the coast to $80-85^{\circ} \mathrm{W}$, where the $L_{p}$ response to $\mathrm{PC} 1$ [+2] (Fig. 11c) is much weaker. This demonstrates that the liquid water path is excited in different ways by the two modes. Further, there is a striking resemblance of the pattern of $L_{p}$ composited on PC2 with the pattern of the MBL depth $z_{i}$ (Fig. 11a, b), with reduced $L_{p}$ corresponding to a 


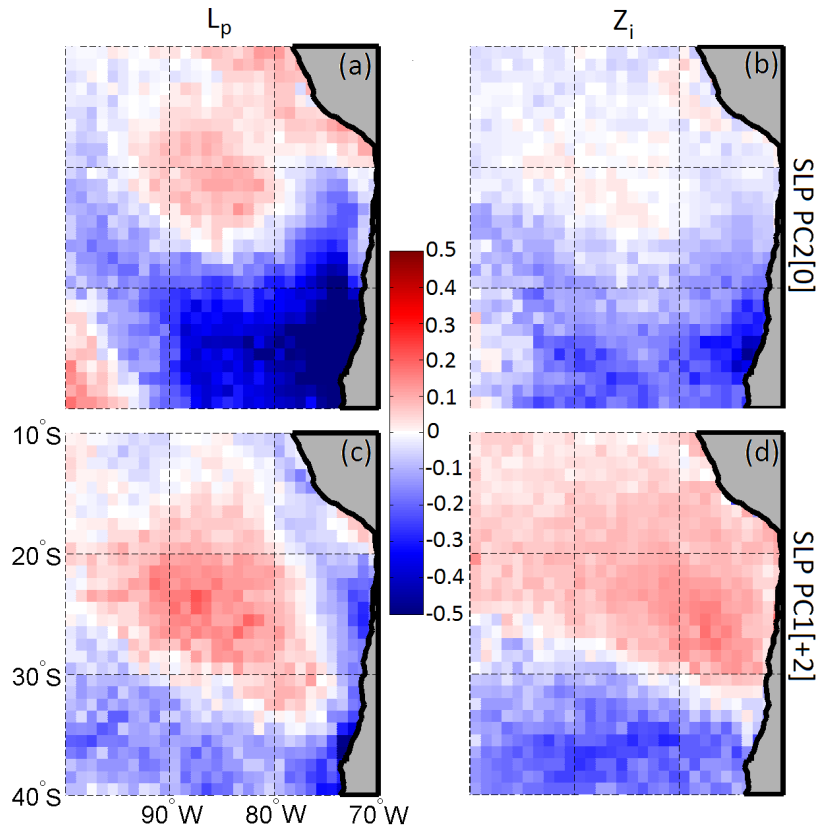

Fig. 11. Fractional composite differences of $L_{p}$ and inversion height, $z_{i}$, on SLP PC2[0] in the top row. For the most representative comparison the bottom row shows equivalent composite differences on SLP PC1[+2], as PC1 correlates most strongly with PC2 two days after PC1.

shallower MBL. This spatial correlation is not prominent in the responses to $\mathrm{PC} 1[+2]$ (Fig. 11c, d), although the major discrepancies between the $L_{p}$ and $z_{i}$ responses to PC1[+2] are in the coastal region out to $5-10^{\circ}$ from the coast, while the responses further out from the coast are actually quite similar. It appears therefore that PC2 is able to excite a significant $L_{p}$ response in the coastal zone to the south of $30^{\circ} \mathrm{S}$ that $\mathrm{PC} 1[+2]$ cannot, and that this response is strongly tied to the depth of the MBL. In general, we find that $L_{p}$ and $z_{i}$ are significantly positively correlated (regardless of meteorology) throughout the region to the south of $20^{\circ} \mathrm{S}$ (not shown). Such a correlation may be anticipated for relatively well-mixed boundary layers if the cloud base height is less variable on synoptic timescales than the cloud top height, for which there is some observational support (Zhou et al., 2006).

These results allow us to hypothesize a plausible physical mechanism by which variability in the subtropical high pressure system can influence both droplet concentrations and cloud macrophysical properties in the coastal zone. A strong high relatively close to the Chilean coast (positive SLP PC2) drives increased subsidence in the coastal zone, particularly south of $25^{\circ} \mathrm{S}$, through the set of processes that cause a coastal low to form (Garreaud et al., 2003). The strong subsidence reduces the MBL depth and $L_{p}$ (Fig. 11a, b), but also drives offshore flow particularly above the MBL (Garreaud et al., 2003, Huneeus et al., 2006). Our SLP PC2 may therefore be an indicator of conditions favorable for the formation of a coastal low.

This has implications for pollution transport. The Andes act to restrict the dispersion of pollutants to the east, while to the west the mean MBL depth increases with distance offshore (from $600 \mathrm{~m}$ near the coast at $30^{\circ} \mathrm{S}, 72^{\circ} \mathrm{W}$ to around $1300 \mathrm{~m}$ at $30^{\circ} \mathrm{S}, 80^{\circ} \mathrm{W}$, Zuidema et al., 2009). We suggest that this mean-state configuration restricts offshore flow and traps pollutants in a relatively narrow region over the land to the west of the Andes and over the shallow near-coastal MBL. These mean conditions are depicted schematically in Fig. 12a. In contrast, we hypothesize that the reduced MBL depth occurring during periods of strong near-coastal high pressure (Fig. 12b) reduces the barrier to offshore flow in the lower free troposphere, allowing atmospheric aerosols and their precursors to spread over a broad region above the MBL (especially at night since offshore flow is strongly diurnal in this region, Rutllant and Garreaud 2004). There may also be offshore flow induced in the MBL itself, but preliminary observations from two flights to $73^{\circ} \mathrm{W}, 30^{\circ} \mathrm{S}$ during the VOCALS Regional Experiment (not shown) revealed considerably stronger offshore flow just above the MBL than in the MBL. Composites on SLP PC 2 of zonal wind at $850 \mathrm{hPa}$ and at the surface are consistent with this picture (not shown). Regardless of whether the offshore flow is most strongly enhanced within or above the MBL, this process would be expected to supply additional aerosols to the MBL and is the likely source of increasing $N_{d}$ over the following few days (as suggested by Fig. 9 which shows a small coastal feature of days of max SLP PC2 that grows and advects northward). This mechanism would tend to induce a negative correlation between $L_{p}$ and $N_{d}$ in the near coastal zone, demonstrating a specific way that meteorology could complicate the interpretation of such a correlation as being due to aerosol indirect effects alone.

Because stronger surface high pressure near the coast has a tendency to occur more frequently when there is stronger high pressure further afield a couple of days earlier (recall the positive correlation between PC2 and PC1[+2]), the nearcoastal changes depicted in the lower panel of Fig. 12 have a tendency to occur against a backdrop of increasing cold advection and cloud cover over the broader SEP. Although we have identified two possible mechanisms for cloud properties to change due to meteorological impacts, they are not independent of each other.

Hence, there are physical mechanisms from which it is rational to expect that some part of the covariability between $N_{d}$ and $f_{c}$ and between $N_{d}$ and $L_{p}$ discussed in Sect. 4.2.1 is driven by meteorological variability rather than by aerosol indirect effects per se. This does not, of course, rule out possible aerosol impacts on cloud macrophysical variables. However, the key point here is that the mechanisms impacting variability in the cloud macrophysics and the cloud microphysics are to a significant degree inseparable. 

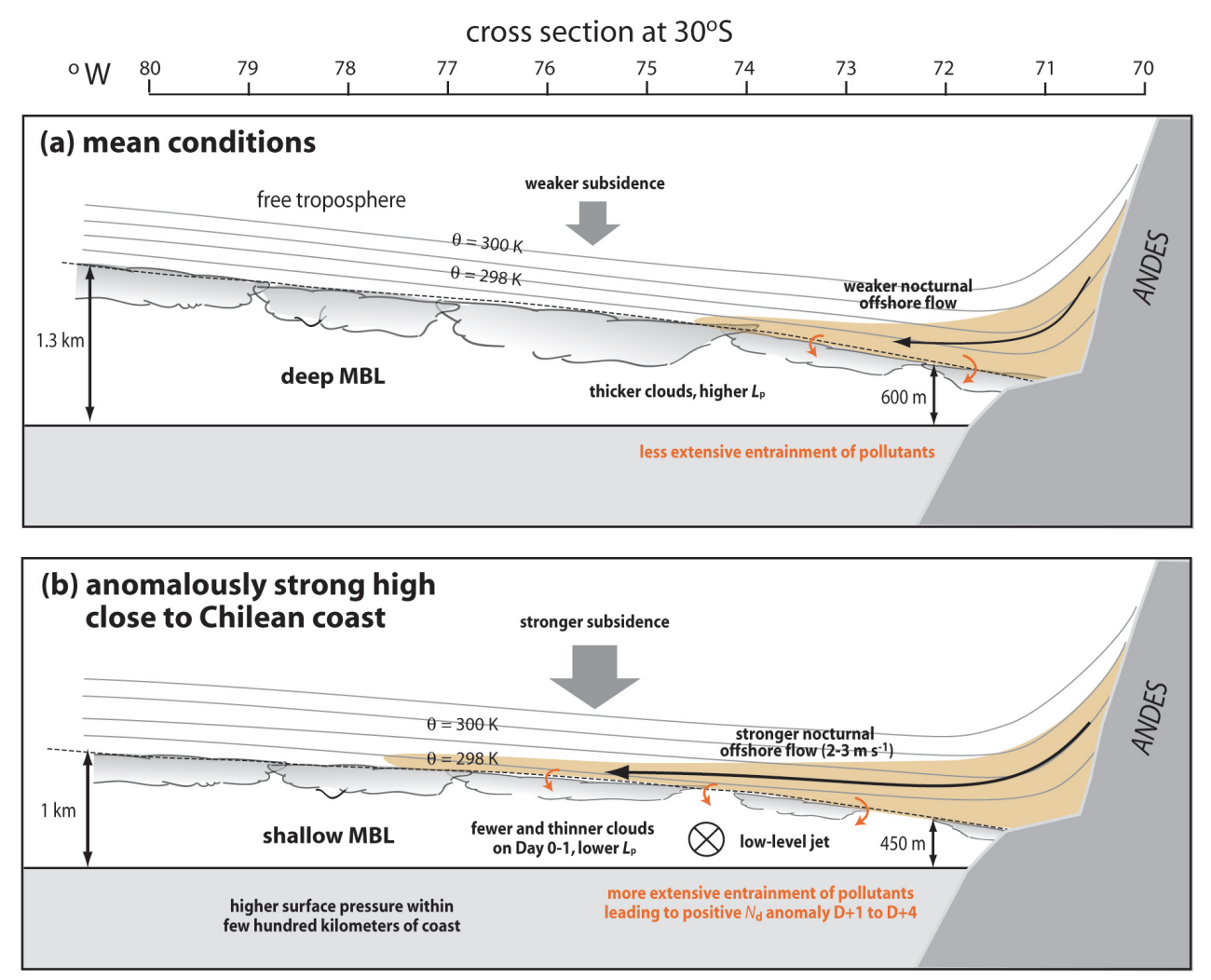

Fig. 12. Conceptual model of hypothesized meteorological mechanism by which cloud variables in the SEP may be influenced by a strong subtropical high near the coast. The top panel demonstrates mean conditions at $30^{\circ} \mathrm{S}$ and the bottom represents what is seen in composite differences on maxima in SLP PC2. Brown shading indicates an airmass containing pollutant aerosols.

\section{Discussion}

Given that cloud and meteorological variables vary on similar timescales, and that a large fraction of seasonal and annual variance in subtropical marine low cloud cover can be explained using single meteorological predictors such as LTS (e.g. Klein and Hartmann, 1993; Wood and Bretherton, 2006), one might expect to see stronger correlations between large scale meteorology and clouds on shorter timescales as well. Consistent with past studies of stratocumulus on subseasonal timescales (e.g. Klein et al., 1997; Xu et al., 2005), we find the correlations of cloud parameters with meteorological parameters to be significant, consistent with simple physical explanations, but quite weak. This leaves a large amount of cloud macrophysical variability unexplained by simple large-scale meteorological variables.

Part of the reason for the lack of a single predictive meteorological control parameter for clouds on short timescales is that other processes, some of which are likely internal MBL processes, operate on timescales short enough that they "average out" in the seasonal mean. It is possible that aerosolcloud interactions independent of meteorology are one such class of processes, but we have seen how untangling the effects of aerosols is going to be particularly challenging given that the meteorological variability helps to control the temporal variability of both aerosols (and thus cloud microphysical properties) and cloud macrophysical properties. In essence then, our results complement an existing body of work that clearly demonstrates that we do not yet have adequate meteorological controls on low cloudiness (see discussions in Bretherton and Hartmann, 2009; Stevens and Brenguier, 2009), and that we cannot therefore adequately control for aerosol influences. We have found little evidence for microphysical variability being a dominant contributor to albedo variability, even though the values of $N_{d}$ above the marine background levels have the potential to alter the mean albedo substantially (Fig. 2). What then, is the outlook for the use of observations to help constrain the magnitude of aerosol indirect effects?

Clearly, it would appear that a priority must be to focus efforts on developing a better understanding of the meteorological factors controlling low cloud macrophysics and corresponding aerosol variability. Breaking the problem down into controls on cloud fraction, liquid water path and droplet concentration, may offer clues regarding the key physical processes. While large scale meteorological variables (e.g. the strength of the subtropical high, or its location) may be significant modulators of low cloud properties, 
we also know that there are mesoscale processes at work, particularly in the coastal zones, that are playing a significant role as well. The mechanisms discussed above, through which synoptic scale meteorological changes lead to observed changes in cloud macrophysical and microphysical properties are hypotheses that can be readily tested with regional models. However, they fall far short of encompassing all processes affecting clouds. There will also be high frequency variability in the meteorology (e.g. gravity waves propagating on the MBL inversion) that is not captured well in the current reanalysis. Also, many important coastal synoptic features, such as coastal lows (Garreaud et al., 2003; Garreaud and Rutllant, 2003) and coastal jet episodes (Garreaud and Munoz, 2005) can change the cloud properties near the coast and their legacy in cloud properties can advect northwestward with the mean flow. While we encountered an index (SLP PC2) that encapsulates events on shorter time and space scales than simple variability in the strength of the subtropical high, some of the cloud development may take place somewhat independently of large scale synoptic forcing. Gaining better conceptual and quantitative understanding of how these mesoscale systems influence cloudiness is important.

It will be also extremely important to understand the mechanisms by which meteorological variability helps drive aerosol variability. Here again, there may be feedbacks associated with cloud processing and coalescence scavenging that would lead to correlations between aerosol/cloud microphysics with meteorology that may be occurring through the meteorological control on cloud macrophysics.

\section{Conclusions}

We explore contributions to the subseasonal temporal and spatial variability of albedo over the southeast Pacific and find that cloud microphysics does not contribute more than $10 \%$ to this albedo variance. Albedo variance is dominated by macrophysics and the covariation between macrophysical parameters of cloud cover and liquid water path, and these features may be masking or suppressing microphysical impacts.

We use indices describing dominant modes of subseasonal large scale variability to examine the meteorological controls on cloud properties. We find that cloud microphysical properties respond in phase with cloud cover and albedo. Cloud droplet concentration is better correlated with these dominant modes than the macrophysical cloud parameters are, and shows the strongest fractional composite response to meteorological changes. This demonstrates how convolved meteorological and aerosol impacts are, making the separation of the two virtually impossible with observations alone. This strong response of microphysics to large scale meteorology, yet minimal contribution to albedo variability indicates that correctly simulating macrophysical variability in a model will be as important as aerosol transport for correctly assessing aerosol indirect effects.

We interpret two ways changes in the subtropical high lead to changes in cloud macrophysical and microphysical variability (and hence albedo). The hypotheses of Klein (1997) and Xu et al. (2005) involving a combination of cold advection and subsidence leading to higher stability is consistent with the satellite observations, but does not explain all cloud anomalies noted, especially in the coastal zone. Further, these hypotheses do not attempt to explain cloud microphysical variability. A second mechanism is presented by which subsidence suppresses MBL depth, allowing for stronger offshore transport of aerosols and a decrease in liquid water path, which seems highly related to variability in SLP close to the Chilean coast and the coastal meteorological response that this induces. This is a mechanism by which $L_{p}$ and $N_{d}$ can negatively correlate due to meteorology rather than second aerosol indirect effects, pointing out that care must be taken when interpreting such correlations.

Our results provide several constraints for model evaluation based on subseasonal variability, and hypothesis that may be testable with regional models. The nature of the correlation of cloud microphysics with the macrophysical variables is one simple constraint beyond the mean state. Capturing the high spatial and temporal variability of $L_{p}$ will be important for correctly representing and identifying feedback processes. In addition, models should be able to accurately represent the pattern and magnitude of the fraction of albedo variance explained by all the variables seen here. It would be useful to examine patterns of cloud variable composites on the large scale meteorological indices presented here. If a model could reproduce the patterns related to subseasonal variability of the system together with the mean states, then this would increase our confidence in the use of the model to quantify aerosol indirect effects.

\section{Appendix A}

\section{Variance of a product}

We let A be a simple product of two variables:

$A=X Y$

We can rephrase each variable $V$ as a sum of a mean $\bar{v}$ and a perturbation $v^{\prime}$, such that $A=\bar{a}+a^{\prime}, X=\bar{x}+x^{\prime}$ and $Y=$ $\bar{y}+y^{\prime}$. So

$A^{2}=\bar{a}^{2}+a^{\prime 2}+2 \bar{a} a^{\prime}$

The mean of the perturbations is 0 by construction, so

$\overline{A^{2}}=\bar{a}^{2}+\overline{a^{\prime 2}}$.

$\overline{a^{\prime 2}}$ is an estimate of the variance of $A$ defined by

$\sigma_{a}^{2}=\lim _{N \rightarrow \infty} \frac{1}{N} \sum_{i=1}^{N}\left(a_{i}-\bar{a}\right)^{2} \approx \overline{a^{\prime 2}}$. 
So the variance of $\mathrm{A}$ is estimated to be

$\overline{a^{\prime 2}}=\overline{\left[\left(\bar{x}+x^{\prime}\right)\left(\bar{y}+y^{\prime}\right)\right]^{2}}-\overline{\left(\bar{x}+x^{\prime}\right)\left(\bar{y}+y^{\prime}\right)^{2}}$.

Expanding the terms and removing mean of single perturbation terms, this becomes

$\overline{a^{\prime 2}}=\bar{y}^{2} \overline{x^{\prime 2}}+\bar{x}^{2} \overline{y^{\prime 2}}+2 \bar{x} \bar{y} \overline{x^{\prime} y^{\prime}}+2 \bar{x} \overline{x^{\prime} y^{\prime 2}}+2 \bar{y} \overline{x^{\prime 2} y^{\prime}}$

$+\overline{x^{\prime 2} y^{\prime 2}}-\left(\overline{x^{\prime} y^{\prime}}\right)^{2}$.

Which can be further algebraically simplified by combining the third order terms and a fourth order term with the first order terms in Eq. (A6).

$\left.\overline{a^{\prime 2}}=\overline{X^{2} y^{\prime 2}}+\overline{x^{\prime 2} Y^{2}}+2(\bar{x})(\bar{y}) \overline{x^{\prime} y^{\prime}}-\left[\overline{x^{\prime 2} y^{\prime 2}}+\overline{\left(x^{\prime} y^{\prime}\right.}\right)^{2}\right]$.

Substituting albedo, for $A, \alpha_{\text {cld }}-\alpha_{\text {clear }}$ for $X$ and $f_{c}$ for $Y$ gives Eq. (5).

We interpret the first term in Eq. (A7) as the contribution of $Y$ variance to the variance of $A$. Besides some leftover fourth order terms, this combines all terms that involve the variance of $Y$. Although the value of $X$ plays a role in this term, the squared coefficients of variation of variable considered in this study were small $\left(\left(\frac{\sigma_{x}}{\bar{x}}\right)^{2}<1\right)$ in the domain considered, so variations in should be relatively unimportant in the term compared to $y^{\prime 2}$ and the average product thus represents the contribution from the variance in $Y$. Similarly the second term represents the contribution from the variance in $X$, and the third the contribution from the covariance between $X$ and $Y$. The final term is fourth order nonlinear effects.

Because it is possible for some of these terms to be negative, the relative contribution of each term is computed by dividing each term by the sum of the absolute values of all terms.

$$
\begin{aligned}
& \overline{a_{\mathrm{abs}}^{\prime 2}}=\left|\overline{X^{2} y^{\prime 2}}\right|+\left|\overline{x^{\prime 2} Y^{2}}\right|+\left|2 \overline{x y} \overline{x^{\prime} y^{\prime}}\right| \\
& +\left|-\overline{x^{\prime 2} y^{\prime} 2}-\left(\overline{x^{\prime} y^{\prime}}\right)^{2}\right|
\end{aligned}
$$

Acknowledgements. The authors thank Chris Bretherton, Mike Wallace, Joel Thornton, for their discussions and guidance. The authors also thank the VOCALS participants, including Rene Garreaud, Thomas Toniazzo, Paquita Zuidema, Grant Allen, Steve Abel, Hugh Coe, Roberto Mechoso and others, for their insightful thoughts and suggestions. This work was supported by National Oceanographic and Atmospheric Administration Grant NA070AR4310282. The ARCS Foundation Fellowship provided additional financial support for the first author. MODIS data were obtained from the NASA Goddard Land Processes data archive. NCEP reanalysis data were obtained from NCEP Climate Diagnostics Center.

Edited by: S. Buehler

\section{References}

Ackerman, A. S., Kirkpatrick, M. P., Stevens, D. E., and Toon, O. B.: The impact of humidity above stratiform clouds on indirect aerosol climate forcing, Nature, 432, 1014-1017, doi:10.1038/nature03174, 2004.

Albrecht, B. A.: Aerosols, cloud microphysics, and fractional cloudiness, Science, 245, 1227-1230, 1989.

Bates, T. S., Lamb, B. K., Guenther, A., Dignon, J., and Stoiber, R. E.: Sulfur emissions to the atmosphere from natural sources, J. Atmos. Chem., 14, 315-337, 1992.

Benkovitz, C. M., Scholtz, M. T., Pacyna, J., Tarrason, L., Dignon, J., Voldner, E. C., Spiro, P. A., Logan, J. A., and Graedel, T. E.: Global gridded inventories of anthropogenic emissions of sulfur and nitrogen, J. Geophys. Res.-Atmos., 101, 29239-29253, 1996.

Bennartz, R.: Global assessment of marine boundary layer cloud droplet number concentration from satellite, J. Geophys. Res.Atmos., 112, D02201, doi:10.1029/2006JD007547, 2007.

Bony, S., Letreut, H., Duvel, J. P., and Kandel, R. S.: Satellite validation of GCM-simulated annual cycle of the earth radiation budget and cloud forcing, J. Geophys. Res.-Atmos., 97, 1806118081, 1992.

Brenguier, J. L., Pawlowska, H., and Schuller, L.: Cloud microphysical and radiative properties for parameterization and satellite monitoring of the indirect effect of aerosol on climate, J. Geophys. Res.-Atmos., 108(14), 8632, doi:10.1029/2002jd002682, 2003.

Bretherton, C. S., Blossey, P. N., and Uchida, J.: Cloud droplet sedimentation, entrainment efficiency, and subtropical stratocumulus albedo, Geophys. Res. Lett., 34, L03813, doi:10.1029/2006g1027648, 2007.

Bretherton, C. S. and Hartmann, D. L.: Large-scale controls on cloudiness, in: Clouds in the perturbed climate system: Their relationship to energy balance, atmospheric dynamics and precipitation, edited by: Heintzenberg, J. and Charleson, R. J., Strungmann forum reports, MIT Press, 217-234, 2009.

Bretherton, C. S., Uttal, T., Fairall, C. W., Yuter, S. E., Weller, R. A., Baumgardner, D., Comstock, K., Wood, R., and Raga, G. B.: The EPIC 2001 stratocumulus study, B. Am. Meteor. Soc., 85, 976-977, doi:10.1175/bams-85-7-967, 2004.

Bretherton, C. S., Widmann, M., Dymnikov, V. P., Wallace, J. M., and Blade, I.: The effective number of spatial degrees of freedom of a time-varying field, J. Climate, 12, 1990-2009, 1999.

Cahalan, R. F., Ridgway, W., Wiscombe, W. J., Bell, T. L., and Snider, J. B.: The albedo of fractal stratocumulus clouds, J. Atmos. Sci., 51, 2434-2455, 1994.

Caldwell, P., Bretherton, C. S., and Wood, R.: Mixed-layer budget analysis of the diurnal cycle of entrainment in southeast Pacific stratocumulus, J. Atmos. Sci., 62, 3775-3791, 2005.

Cess, R. D.: Climate change - appraisal of atmospheric feedback mechanisms employing zonal climatology, J. Atmos. Sci., 33, 1831-1843, 1976.

Fu, Q. and Liou, K. N.: On the correlated k-distribution method for radiative transfer in nonhomogenous atmospheres, J. Atmos. Sci., 49, 2139-2156, 1992.

$\mathrm{Fu}, \mathrm{Q}$. and Liou, K. N.: Parameterization of the radiative properties pf cirrus clouds, J. Atmos. Sci., 50, 2008-2025, 1993.

Garreaud, R. D. and Munoz, R. C.: The low-level jet off the west coast of subtropical South America: Structure and variability, 
Mon. Weather Rev., 133, 2246-2261, 2005.

Garreaud, R. D., Rutllant, J., Quintana, J., Carrasco, J., and Minnis, P.: Cimar-5: A snapshot of the lower troposphere over the subtropical southeast Pacific, B. Am. Meteor. Soc., 82, 2193-2207, 2001.

Garreaud, R. D. and Rutllant, J.: Coastal lows along the subtropical west coast of south america: Numerical simulation of a typical case, Mon. Wea. Rev., 131, 891-908, 2003.

Han, Q. Y., Rossow, W. B., and Lacis, A. A.: Near-global survey of effective droplet radii in liquid water clouds using isccp data, J. Climate, 7, 465-497, 1994.

Huneeus, N., Gallardo, L., and Rutllant, J. A.: Offshore transport episodes of anthropogenic sulfur in northern Chile: Potential impact on the stratocumulus cloud deck, Geophys. Res. Lett., 33, L19819, doi:10.1029/2006g1026921, 2006.

Kalnay, E., Kanamitsu, M., Kistler, R., Collins, W., Deaven, D., Gandin, L., Iredell, M., Saha, S., White, G., Woollen, J., Zhu, Y., Chelliah, M., Ebisuzaki, W., Higgins, W., Janowiak, J., Mo, K. C., Ropelewski, C., Wang, J., Leetmaa, A., Reynolds, R., Jenne, R., and Joseph, D.: The NCEP/NCAR 40-year reanalysis project, B. Am. Meteor. Soc., 77, 437-471, 1996.

Kaufman, Y. J., Koren, I., Remer, L. A., Rosenfeld, D., and Rudich, Y.: The effect of smoke, dust, and pollution aerosol on shallow cloud development over the Atlantic ocean, Proc. Natl. Acad. Sci., 102, 11207-11212, doi:10.1073/pnas.0505191102, 2005.

King, M. D. and Harshvardhan: Comparative accuracy of selected multiple-scattering approximations, J. Atmos. Sci., 43, 784-801, 1986.

King, M. D., Tsay, S.-C., Platnick, S. E., Wang, M., and Liou, K.N.: Cloud retrieval algorithms for MODIS: Optical thickness, effective particle radius, and thermodynamic phase, in, NASA, MODIS Algorithm Theoretical Basis Doc, 1997.

Klein, S. A., Hartmann, D. L., and Norris, J. R.: On the relationships among low-cloud structure, sea-surface temperature, and atmospheric circulation in the summertime northeast Pacific, J. Climate, 8, 1140-1155, 1995.

Klein, S. A. and Hartmann, D. L.: The seasonal cycle of low stratiform clouds, J. Climate, 6, 1587-1606, 1993.

Klein, S. A.: Synoptic variability of low-cloud properties and meteorological parameters in the subtropical trade wind boundary layer, J. Climate, 10, 2018-2039, 1997.

Lebsock, M. D., Stephens, G. L., and Kummerow, C.: Multisensor satellite observations of aerosol effects on warm clouds, J. Geophys. Res., 113, D15205, doi:10.1029/2008jd009876, 2008.

Loeb, N. G., and Kato, S.: Top-of-atmosphere direct radiative effect of aerosols over the tropical oceans from the clouds and the earth's radiant energy system (CERES) satellite instrument, J. Climate, 15, 1474-1484, 2002.

Lohmann, U. and Feichter, J.: Global indirect aerosol effects: A review, Atmos. Chem. and Phys., 5, 715-737, 2005.

Martin, G. M., Johnson, D. W., and Spice, A.: The measurement and parameterization of effective radius of droplets in warm stratocumulus clouds, J. Atmos. Sci., 51, 1823-1842, 1994.

Matheson, M. A., Coakley, J. A., and Tahnk, W. R.: Aerosol and cloud property relationships for summertime stratiform clouds in the northeastern Atlantic from advanced very high resolution radiometer observations, J. Geophys. Res.-Atmos., 110, D24204, doi:10.1029/2005jd006165, 2005.

Mauger, G. S. and Norris, J. R.: Meteorological bias in satellite estimates of aerosol-cloud relationships, Geophys. Res. Lett., 34, L16824, doi:10.1029/2007g1029952, 2007.

Norris, J. R. and Leovy, C. B.: Interannual variability in stratiform cloudiness and sea-surface temperature, J. Climate, 7, 19151925, 1994.

North, G. R., Bell, T. L., Cahalan, R. F., and Moeng, F. J.: Sampling errors in the estimation of empirical orthogonal functions, Mon. Weather Rev., 110, 699-706, 1982.

Platnick, S. and Twomey, S.: Determining the susceptibility of cloud albedo to changes in droplet concentration with the advanced very high-resolution radiometer, J. Appl. Meteorol., 33, 334-347, 1994.

Quaas, J., Boucher, O., Bellouin, N., and Kinne, S.: Satellite-based estimate of the direct and indirect aerosol climate forcing, J. Geophys. Res.-Atmos., 113, D05204, doi:10.1029/2007jd008962, 2008.

Richter, I. and Mechoso, C. R.: Orographic influences on the annual cycle of Namibian stratocumulus clouds, Geophys. Res. Lett., 31, L24108, doi10.1029/2004g1020814, 2004.

Rossow, W. B., Delo, C., and Cairns, B.: Implications of the observed mesoscale variations of clouds for Earth's radiation budget, J. Climate, 15, 557-585, 2002.

Rozendaal, M. A., Leovy, C. B., and Klein, S. A.: An observational study of diurnal-variations of marine stratiform cloud, J. Climate, 8, 1795-1809, 1995.

Rutllant, J. A. and Garreaud, R. D.: Episodes of strong flow down the western slope of the subtropical Andes, Mon. Weather Rev., 132, 611-622, 2004.

Schuller, L., Bennartz, R., Fischer, J., and Brenguier, J.-L.: An Algorithm for the Retrieval of Droplet Number Concentration and Geometrical Thickness of Stratiform Marine Boundary Layer Clouds Applied to MODIS Radiometric Observations, J. Appl Meteorol., 44, 28-38, 2005.

Slingo, A. and Schrecker, H. M.: On the shortwave radiative properties of stratiform water clouds, Q. J. Roy. Meteor. Soc., 108, 407-426, 1982.

Stevens, B. and Brenguier, J.-L.: Cloud controlling factors: Low clouds, in: Clouds in the perturbed climate system: Their relationship to energy balance, atmospheric dynamics and precipitation, edited by: Heintzenberg, J. and Charleson, R. J., Strungmann forum reports, MIT Press, 173-196, 2009.

Szczodrak, M., Austin, P. H., and Krummel, P. B.: Variability of optical depth and effective radius in marine stratocumulus clouds, J. Atmos. Sci., 58, 2912-2926, 2001.

Takahashi, K. and Battisti, D. S.: Processes controlling the mean tropical Pacific precipitation pattern. Part ii: The SPCZ and the southeast Pacific dry zone, J. Climate, 20, 5696-5706, doi:10.1175/2007jcli1656.1, 2007.

Twohy, C. H., Petters, M. D., Snider, J. R., Stevens, B., Tahnk, W., Wetzel, M., Russell, L., and Burnet, F.: Evaluation of the aerosol indirect effect in marine stratocumulus clouds: Droplet number, size, liquid water path, and radiative impact, J. Geophys. Res.Atmos., 110, D08203, doi:10.1029/2004jd005116, 2005.

Twomey, S.: Pollution and planetary albedo, Atmos. Environ., 8, 1251-1256, 1974.

Wang, S. P., Wang, Q., and Feingold, G.: Turbulence, condensation, and liquid water transport in numerically simulated nonprecipitating stratocumulus clouds, J. Atmos. Sci., 60, 262-278, 2003.

Wilks, D.: Statistical Methods in the Atmospheric Sciences, 
2nd edition, Internation Geophysical Series, 91, edited by: Dmowska, R., Hartmann, D., and Rossby, H. T., Elsevier, 465$528,2006$.

Wood, R., Bretherton, C. S., and Hartmann, D. L.: Diurnal cycle of liquid water path over the subtropical and tropical oceans, Geophys. Res. Lett., 29, D08203, doi:10.1029/2002g1015371, 2002.

Wood, R. and Bretherton, C. S.: Boundary layer depth, entrainment, and decoupling in the cloud-capped subtropical and tropical marine boundary layer, J. Climate, 17, 3576-3588, 2004.

Wood, R. and Bretherton, C. S.: On the relationship between stratiform low cloud cover and lower-tropospheric stability, J. Climate, 19, 6425-6432, 2006.

Wood, R., Comstock, K. K., Bretherton, C. S., Cornish, C., Tomlinson, J., Collins, D. R., and Fairall, C.: Open cellular structure in marine stratocumulus sheets, J. Geophys. Res.-Atmos., 113, D12207, doi:10.1029/2007jd009371, 2008.

Wood, R. and Hartmann, D. L.: Spatial variability of liquid water path in marine low cloud: The importance of mesoscale cellular convection, J. Climate, 19, 1748-1764, 2006.

Wood, R.: Cancellation of aerosol indirect effects in marine stratocumulus through cloud thinning, J. Atmos. Sci., 64, 26572669, doi:10.1175/jas3942.1, 2007.

Xu, H. M., Xie, S. P., and Wang, Y. Q.: Subseasonal variability of the southeast Pacific stratus cloud deck, J. Climate, 18, 131-142, 2005 .
Xue, H. W. and Feingold, G.: Large-eddy simulations of trade wind cumuli: Investigation of aerosol indirect effects, J. Atmos. Sci., 63, 1605-1622, 2006.

Yang, M., Blomquist, B. W., and Huebert, B. J.: Constraining the concentration of the hydroxyl radical in a stratocumulus-topped marine boundary layer from sea-to-air eddy covariance flux measurements of dimethylsulfide, Atmos. Chem. Phys., 9, 92259236, 2009, http://www.atmos-chem-phys.net/9/9225/2009/.

Zhang, M. H., Lin, W. Y., Klein, S. A., Bacmeister, J. T., Bony, S., Cederwall, R. T., Del Genio, A. D., Hack, J. J., Loeb, N. G., Lohmann, U., Minnis, P., Musat, I., Pincus, R., Stier, P., Suarez, M. J., Webb, M. J., Wu, J. B., Xie, S. C., Yao, M. S., and Zhang, J. H.: Comparing clouds and their seasonal variations in 10 atmospheric general circulation models with satellite measurements, J. Geophys. Res.-Atmos., 110, doi:10.1029/2004jd005021, 2005.

Zhou, M. Y., Zeng, X. B., Brunke, M., Zhang, Z. H., and Fairall, C.: An analysis of statistical characteristics of stratus and stratocumulus over eastern Pacific, Geophys. Res. Lett., 33, L02807, doi:10.1029/2005g1024796, 2006.

Zuidema, P., Painemal, D., de Szoeke, S., and Fairall, C.: Stratocumulus cloud-top height estimates and their climatic implications, J. Climate, 22, 4652-4666, doi:10.1175/2009jcli2708.1, 2009. 